\title{
PIE on Safety-Tested AGR-1 Compact 4-2-2
}

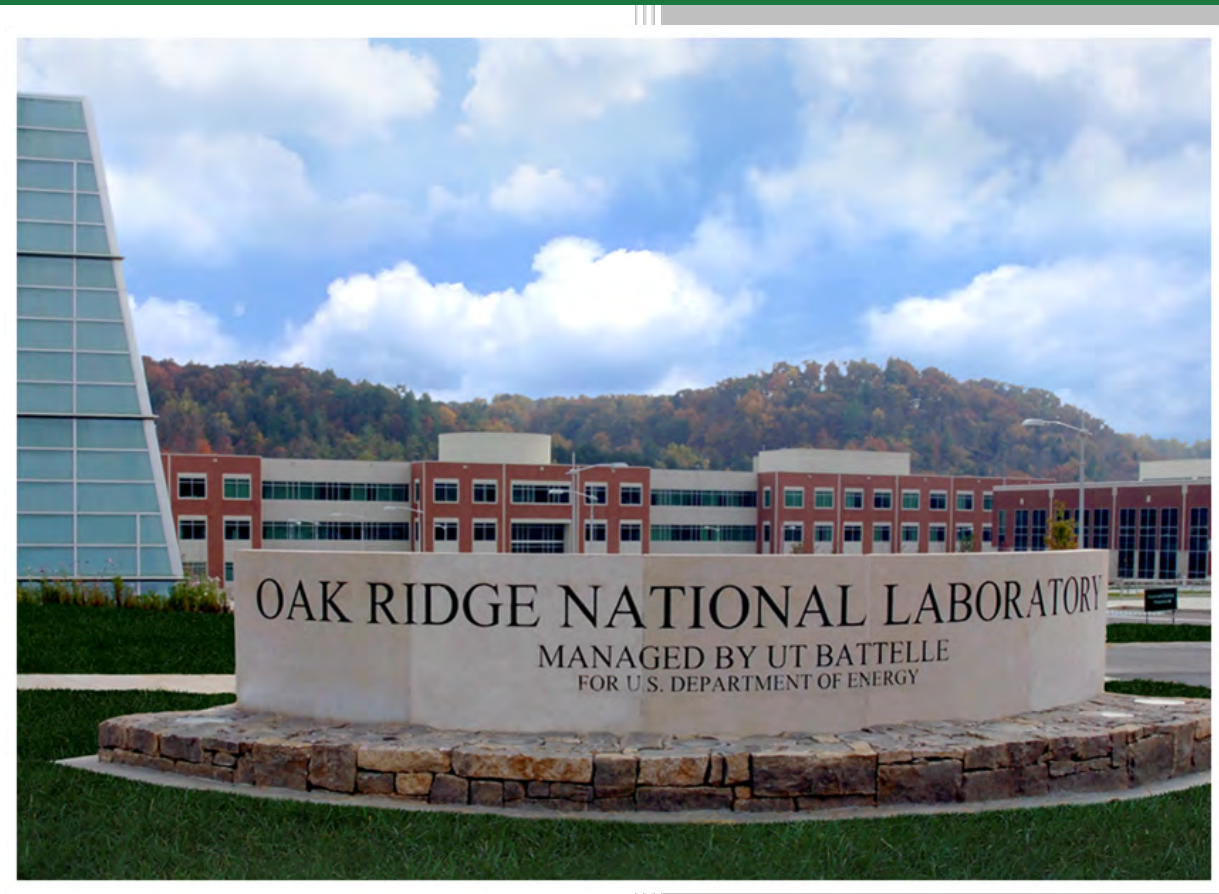

Approved for public release.

Distribution is unlimited.

John D. Hunn

Robert N. Morris

Charles A. Baldwin

Fred C. Montgomery

Tyler J. Gerczak

March 2015 


\title{
DOCUMENT AVAILABILITY
}

Reports produced after January 1, 1996, are generally available free via US Department of Energy (DOE) SciTech Connect.

\section{Website http://www.osti.gov/scitech/}

Reports produced before January 1, 1996, may be purchased by members of the public from the following source:

\author{
National Technical Information Service \\ 5285 Port Royal Road \\ Springfield, VA 22161 \\ Telephone 703-605-6000 (1-800-553-6847) \\ TDD 703-487-4639 \\ Fax 703-605-6900 \\ E-mail info@ntis.gov \\ Website http://www.ntis.gov/help/ordermethods.aspx
}

Reports are available to DOE employees, DOE contractors, Energy Technology Data Exchange representatives, and International Nuclear Information System representatives from the following source:

Office of Scientific and Technical Information

PO Box 62

Oak Ridge, TN 37831

Telephone 865-576-8401

Fax 865-576-5728

E-mail reports@osti.gov

Website http://www.osti.gov/contact.html

This report was prepared as an account of work sponsored by an agency of the United States Government. Neither the United States Government nor any agency thereof, nor any of their employees, makes any warranty, express or implied, or assumes any legal liability or responsibility for the accuracy, completeness, or usefulness of any information, apparatus, product, or process disclosed, or represents that its use would not infringe privately owned rights. Reference herein to any specific commercial product, process, or service by trade name, trademark, manufacturer, or otherwise, does not necessarily constitute or imply its endorsement, recommendation, or favoring by the United States Government or any agency thereof. The views and opinions of authors expressed herein do not necessarily state or reflect those of the United States Government or any agency thereof. 


\title{
PIE ON SAFETY-TESTED AGR-1 COMPACT 4-2-2
}

\author{
John D. Hunn \\ Robert N. Morris \\ Charles A. Baldwin \\ Fred C. Montgomery \\ Tyler J. Gerczak
}

Date Published: March 2015

\author{
Work sponsored by \\ US DEPARTMENT OF ENERGY \\ Office of Nuclear Energy - Advanced Reactor Technologies \\ under the \\ Advanced Gas Reactor Fuel Development and Qualification Program
}

Prepared by
OAK RIDGE NATIONAL LABORATORY

Oak Ridge, TN 37831-6283

managed by

UT-BATTELLE, LLC

for the

US DEPARTMENT OF ENERGY

under contract DE-AC05-00OR22725 



\section{TABLE OF CONTENTS}

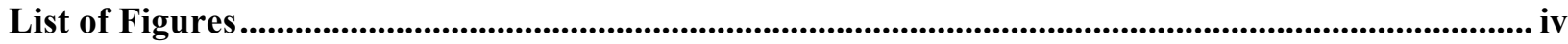

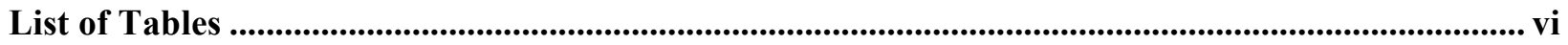

List of Acronyms .................................................................................................................................................... vii

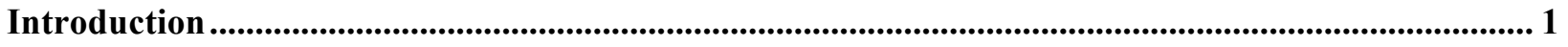

Standard examination procedure .................................................................................................................. 2

Furnace testing results...................................................................................................................................... 4

DLBL results .................................................................................................................................................. 9

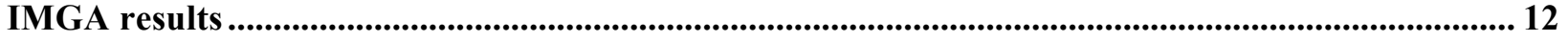

Microstructural analysis of individual particles ........................................................................................ 15

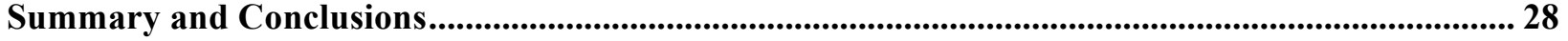

Acknowledgments ................................................................................................................................................. 30

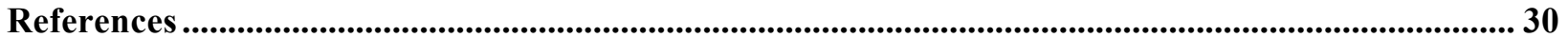




\section{LIST OF FIGURES}

Figure 1. Particles deconsolidated and riffled for IMGA.

Figure 2. Collection of ${ }^{110 \mathrm{~m}} \mathrm{Ag}$ from Compact 4-2-2 during multiple-temperature safety testing. Data points show the end of each cup collection period, when resident cup was exchanged for a new cup.

Figure 3. Collection of ${ }^{110 \mathrm{~m}} \mathrm{Ag}$ from Compact 4-2-2 during multiple-temperature safety testing. Data points show the middle of each cup collection period..

Figure 4. Collection of ${ }^{110 \mathrm{~m}} \mathrm{Ag}$ from Compact 3-3-2 during $1600^{\circ} \mathrm{C}$ safety testing that was preceded by unplanned thermal cycling (due to issues with power supply) and followed by planned thermal cycling. Additional silver was released each time the temperature was cycled [Hunn, Morris, and Baldwin 2012]

Figure 5. Collection of other radioisotopes from Compact 4-2-2. Data points show the end of each cup collection period.

Figure 6. Collection of other radioisotopes from Compact 4-2-2. Data points show the end of each cup collection period.

Figure 7. Ratio of ${ }^{144} \mathrm{Ce}$ retained in 103 particles randomly-selected from Compact 4-2-2 versus calculated inventory, adjusted for variation in fissionable material and burnup with the measured ${ }^{137} \mathrm{Cs}$ activity.

Figure 8. Ratio of ${ }^{154}$ Eu retained in 103 particles randomly-selected from Compact 4-2-2 versus calculated inventory, adjusted for variation in fissionable material and burnup with the measured ${ }^{137} \mathrm{Cs}$ activity......

Figure 9. Ratio of ${ }^{110 \mathrm{~m}} \mathrm{Ag}$ retained in 103 particles randomly-selected from Compact 4-2-2 versus calculated inventory, adjusted for variation in fissionable material and burnup with the measured ${ }^{137} \mathrm{Cs}$ activity. Note that the ${ }^{110 \mathrm{~m}} \mathrm{Ag}$ activity in these particles was very low at the time of analysis and uncertainty in peak analysis ranged from $\sim 20 \%$ for particles with more silver to $\sim 53 \%$ for particles with barely detectable silver. The 64 particles with undetectable inventory contained less than a minimum detectable $\mathrm{M} / \mathrm{C}$ of $0.21-0.34$.

Figure 10. Ratio of ${ }^{110 \mathrm{~m}} \mathrm{Ag}$ retained in 52 particles randomly-selected from Compact 5-2-1 versus calculated inventory, adjusted for variation in fissionable material and burnup with the measured ${ }^{137} \mathrm{Cs}$ activity. Note that the ${ }^{110 \mathrm{~m}} \mathrm{Ag}$ activity in these particles was low at the time of analysis and uncertainty in peak analysis ranged from $\sim 12 \%$ for particles with more silver to $\sim 46 \%$ for particles with barely detectable silver. The 52 particles with undetectable inventory contained less than a minimum detectable $\mathrm{M} / \mathrm{C}$ of $0.22-0.27$.

Figure 11. Orthogonal pairs of $\mathrm{X}$-ray tomographs near midplane for three particles from Compact 4-2-2: (a) Particle 422-RS71 with high ${ }^{110 \mathrm{~m}} \mathrm{Ag}$ release $(\mathrm{M} / \mathrm{C}<0.37)$, (b) Particle 422-RS11 with moderate ${ }^{110 \mathrm{~m}} \mathrm{Ag}$ release $(\mathrm{M} / \mathrm{C}=0.45)$, and (c) Particle 422-RS21 with very low ${ }^{110 \mathrm{~m}} \mathrm{Ag}$ release $(M / C=1.06)$. Streaks extending from top and bottom of kernels are reconstruction artifacts.

Figure 12. Optical micrographs near midplane of particles from Compact 4-2-2: (a\&b) Particle 422RS57 with high ${ }^{110 \mathrm{~m}} \mathrm{Ag}$ release $(\mathrm{M} / \mathrm{C}<0.38)$, (c) Particle $422-\mathrm{RS} 45$ with moderate ${ }^{110 \mathrm{~m}} \mathrm{Ag}$ release $(\mathrm{M} / \mathrm{C}=0.43)$, and $(\mathrm{d})$ Particle $422-\mathrm{RS} 23$ with very low ${ }^{110 \mathrm{~m}} \mathrm{Ag}$ release $(\mathrm{M} / \mathrm{C}=1.21)$. If kernel and buffer were detached from outer three coating layers, they may have shifted before backpotting and not be near midplane.

Figure 13. SEI/BEC-paired images of Particle 422-RS57 with high ${ }^{110 \mathrm{~m}} \mathrm{Ag}$ release $(\mathrm{M} / \mathrm{C}<0.38)$ shown in Figure 12a.

Figure 14. SEI/BEC-paired images of Particle 422-RS57 with high ${ }^{110 \mathrm{~m}} \mathrm{Ag}$ release $(\mathrm{M} / \mathrm{C}<0.38)$ shown in Figure 13. Dashed diamonds or squares indicate relatively-lower signal from Pd or U.

Figure 15. SEI/BEC-paired images of Particle 422-RS45 with moderate ${ }^{110 \mathrm{~m}} \mathrm{Ag}$ release $(\mathrm{M} / \mathrm{C}=0.43)$ shown in Figure 12c. 
Figure 16. SEI/BEC-paired images of Particle 422-RS45 with moderate ${ }^{110 \mathrm{~m}} \mathrm{Ag}$ release $(\mathrm{M} / \mathrm{C}=0.43)$ shown in Figure 15. Dashed diamonds or squares indicate relatively-lower signal from Pd or U.

Figure 17. SEI/BEC-paired images of Particle 422-RS23 with very low ${ }^{110 \mathrm{~m}} \mathrm{Ag}$ release $(\mathrm{M} / \mathrm{C}=1.21)$

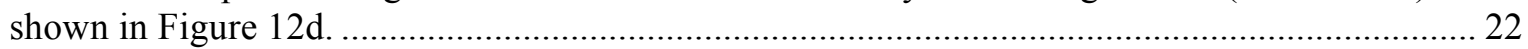

Figure 18. SEI/BEC-paired images of Particle $422-\mathrm{RS} 23$ with very low ${ }^{110 \mathrm{~m}} \mathrm{Ag}$ release $(\mathrm{M} / \mathrm{C}=1.21)$

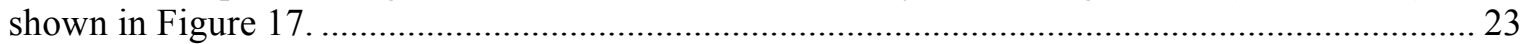

Figure 19. Polished section near midplane of Particle 422-RS60 with high ${ }^{110 \mathrm{~m}} \mathrm{Ag}$ release $(\mathrm{M} / \mathrm{C}<0.38)$ : (a\&b) optical micrographs and (c) SEI image. ....

Figure 20. SEI montage of Compact 4-2-2 Particle 422-RS60 shown in Figure 19............................... 26

Figure 21. BEC montage of Compact 4-2-2 Particle 422-RS60 shown in Figure 19............................. 27 


\section{LIST OF TABLES}

Table 1. Cumulative releases from Compact 4-2-2 of radioactive isotopes detected on the CCCTF furnace internals at the end of the test, and the final distribution of these radioisotopes on the various components

Table 2. Distribution of strontium, europium, and cesium outside of $\mathrm{SiC}$ after safety testing.................... 9

Table 3. Exposed compact inventory fractions for $\mathrm{U}$ and $\mathrm{Pu}$ detected by $\mathrm{LBL}$ for furnace-tested

Compact 4-2-2 and as-irradiated Compact 4-4-2

Table 4. Compact inventory fractions of important gamma emitting fission products detected by

LBL of AGR-1 irradiated Compact 4-2-2 (analyzed by gamma spectrometric method)...

Table 5. Radioactive isotopes detected in particles from Compact 4-2-2 


\section{LIST OF ACRONYMS}

$\begin{array}{ll}\text { 3D } & \text { Three-Dimensional } \\ \text { AGR } & \text { Advanced Gas Reactor } \\ \text { ART } & \text { Advanced Reactor Technologies } \\ \text { ATR } & \text { Advanced Test Reactor (INL) } \\ \text { BEC } & \text { Backscattered Electron Composition } \\ \text { CCCTF } & \text { Core Conduction Cooldown Test Facility (ORNL) } \\ \text { DLBL } & \text { Deconsolidation Leach-Burn-Leach } \\ \text { EDS } & \text { Energy Dispersive Spectrometry } \\ \text { FIMA } & \text { Fissions per Initial Metal Atom } \\ \text { HFEF } & \text { Hot Fuel Examination Facility (INL) } \\ \text { HTGR } & \text { High Temperature Gas-cooled Reactor } \\ \text { IFEL } & \text { Irradiated Fuels Examination Laboratory (ORNL Building 3525) } \\ \text { IMGA } & \text { Irradiated Microsphere Gamma Analyzer (ORNL) } \\ \text { INL } & \text { Idaho National Laboratory } \\ \text { IPyC } & \text { Inner Pyrolytic Carbon (layer) } \\ \text { LEU } & \text { Low Enriched Uranium } \\ \text { M/C } & \text { Measured versus Calculated ratio } \\ \text { OPyC } & \text { Outer Pyrolytic Carbon (layer) } \\ \text { ORNL } & \text { Oak Ridge National Laboratory } \\ \text { PIE } & \text { Post-Irradiation Examination } \\ \text { RS } & \text { Randomly-Selected particles } \\ \text { SEI } & \text { Secondary Electron Imaging } \\ \text { SEM } & \text { Scanning Electron Microscope } \\ \text { SiC } & \text { Silicon Carbide (layer) } \\ \text { TRISO } & \text { TRi-ISOtropic (coated particles) } \\ \text { UCO } & \text { Uranium Carbide/uranium Oxide (kernels) } \\ \text { Z } & \text { Atomic number }\end{array}$





\section{INTRODUCTION}

Post-irradiation examination (PIE) is being performed in support of tristructural isotropic (TRISO) coated particle fuel development and qualification for High Temperature Gas-cooled Reactors (HTGRs). AGR-1 was the first in a series of TRISO fuel irradiation experiments initiated in 2006 under the Advanced Gas Reactor (AGR) Fuel Development and Qualification Program [Petti et al. 2010]; this work continues to be funded by the Department of Energy's Office of Nuclear Energy in support of Advanced Reactor Technologies (ART). AGR-1 fuel compacts were fabricated at Oak Ridge National Laboratory (ORNL) in 2006 and irradiated for 3 years in the Advanced Test Reactor (ATR) at Idaho National Laboratory (INL) to demonstrate and evaluate fuel performance under HTGR irradiation conditions. PIE is being performed at INL and ORNL to study how the fuel behaved during irradiation, and to test fuel performance during exposure to elevated temperatures at or above temperatures that could occur during a depressurized conduction cooldown event. This report summarizes safety testing and post-safety testing PIE recently completed at ORNL on irradiated AGR-1 Compact 4-2-2.

Compact 4-2-2 was an AGR-1 Variant 3 fuel type [Hunn and Lowden 2006; Hunn, Montgomery, and Pappano 2006]. AGR-1 Baseline and Variant 3 fuel particles had similar characteristics except for the silicon carbide layer $(\mathrm{SiC})$, which was deposited in Variant 3 at a lower temperature using an argon diluent; this resulted in a finer-grained, more-equiaxed structure [Hunn, Savage, and Silva 2012]. Detailed fabrication and characterization data for the pre-irradiated compacts can be found in the individual data packages and pre-irradiation summary report.

AGR-1 Compact 4-2-2 was irradiated at ATR to an average calculated burnup of $16.6 \%$ fissions per initial metal atom (FIMA) and an average calculated fast fluence of $3.73 \cdot 10^{25} \mathrm{n} / \mathrm{m}^{2}$, at a calculated timeaveraged and volume-averaged temperature of approximately $1065^{\circ} \mathrm{C}$. After capsule disassembly in the INL Hot Fuel Examination Facility (HFEF), metrology [Demkowicz et al. 2011] and gamma scanning [Harp 2013] were performed. The compact was then shipped to ORNL for safety testing and additional PIE. The Compact 4-2-2 safety test began on May 5, 2014 and ended on June 4, 2014.

Safety testing was performed in the ORNL Core Conduction Cooldown Test Facility (CCCTF). Standard safety tests involve heating compacts to maximum temperatures of 1600,1700 , or $1800^{\circ} \mathrm{C}$ for typically 300 hours, where $1600^{\circ} \mathrm{C}$ is the expected maximum temperature during an HTGR depressurization conduction cooldown event, while 1700 and $1800^{\circ} \mathrm{C}$ explore the performance margin. The Compact 4-2-2 safety test was conducted using multiple hold temperatures from $1000-1600^{\circ} \mathrm{C}$, according to the examination plan [Demkowicz 2014], to investigate fission product ${ }^{1}$ retention at temperatures below $1600^{\circ} \mathrm{C}$ and during thermal cycling, with particular emphasis on silver retention behavior. Previous safety tests produced unusual silver releases when temperatures were inadvertently or intentionally cycled between room temperature and $1600^{\circ} \mathrm{C}$ [Hunn, Morris, and Baldwin 2012]; the Compact 4-2-2 test was designed to reproduce and explore these observations.

After completion of the safety test, the compact was examined with a standard set of analyses that included the following: (1) detection of exposed fission products by Deconsolidation-Leach-Burn-Leach (DLBL), (2) measurement of the gamma-emitting isotopic inventory within individual particles with the ORNL Irradiated Microsphere Gamma Analyzer (IMGA), and (3) microstructural examination by highresolution x-ray tomography and materialography. The equipment and methods used for the safety testing and post-safety testing PIE are summarized in the next section of this report and have previously been described in detail [Baldwin et al. 2012; Hunn et al. 2013-1]. This report also provides a summary of the results of the safety tests and subsequent PIE. Preliminary trends are discussed, but final conclusions are reserved for a comprehensive AGR-1 PIE summary that will include data from PIE of other compacts from the AGR-1 irradiation test.

\footnotetext{
${ }^{1}$ In this paper, the term "fission product" is used in the general sense to refer to all the post-fission isotopes remaining at the end of the irradiation test. These include: isotopes directly generated by the fission process, isotopes generated by neutron activation, isotopes generated by radioactive decay, and residual uranium.
} 


\section{STANDARD EXAMINATION PROCEDURE}

[edited and expanded extract from Hunn et al. 2013-2]

Standard AGR-1 safety testing was performed in flowing helium, with compacts held at a constant maximum test temperature for $300 \mathrm{~h}$ [Morris et al. 2014]. As mentioned above, the Compact 4-2-2 safety test was a specialized test conducted using multiple hold temperatures from $1000-1600^{\circ} \mathrm{C}$. Details of temperatures and hold times used in this test are presented with the safety test results in the next section. During the test period, metallic elements released from the compacts were collected by a water-cooled cold finger at the top of the CCCTF furnace, and gaseous fission products were extracted from the helium sweep gas as it passed through liquid nitrogen-cooled cold traps located downstream. Deposition cups attached to the in-furnace cold finger were periodically removed and analyzed by gamma spectrometry and the sweep gas traps were constantly monitored for gamma activity throughout each run.

As originally designed, the cooled-deposition cups have a high efficiency for collection of silver and cesium at $1600-1800^{\circ} \mathrm{C}$, and the sweep gas trap system has a good sensitivity to release of ${ }^{85} \mathrm{Kr}$. Timedependent monitoring of europium and strontium (not originally part of the CCCTF design) includes a larger uncertainty, due to the fact that these elements can be retained by the graphite and tantalum furnace internals; analysis of the CCCTF furnace internals at the end of each test is important for accurate assessment of the total cumulative release of these elements. For a typical AGR-1 $1600^{\circ} \mathrm{C}$ safety test in the CCCTF, the fraction of europium that eventually accumulated on the deposition cups was only 10 $13 \%$, while silver collection efficiency was typically above $95 \%$.

After completion of the safety testing, acid leaching and additional analyses were performed on the deposition cups and CCCTF furnace internals (graphite fuel holder, tantalum furnace liner, and tantalum gas inlet line) to measure the activity from the radioactive fission products that had been transferred from the compact to these various furnace components. For a standard (single-temperature) safety test, an average deposition cup collection efficiency is determined for each monitored fission product by measuring the total release from the compact (summing the inventories measured on the deposition cups, graphite holder, and tantalum furnace internals), and calculating the fraction of the total that went to the cups. The average collection efficiency can be used to adjust the time-dependent deposition cup data to estimate the time-dependent fission product release from the compact. However, for the Compact 4-2-2 safety test, this approach is not viable because the cup collection efficiency is expected to vary as a function of temperature, so an average taken over a time period involving holds at different temperatures would not be representative of the average collection efficiency during each hold. Therefore, timedependent data for this test are simply presented in terms of the fission product fractions collected on the deposition cups.

Additional post-safety test PIE consisted of leach-burn-leach, individual particle gamma spectrometry, $\mathrm{x}$-ray tomography, and materialography. The compact was first electrolytically deconsolidated in nitric acid to break up the matrix carbon and release the TRISO-coated particles. Particles and matrix residue were then leached twice with hot nitric acid in a Soxhlet extractor to dissolve any soluble elements in the matrix residue or on the surface of the particles. This leaching step will also dissolve uranium in exposed kernels of particles with fractured TRISO coatings (no exposed kernels were detected). After the deconsolidation-leach (DL), particles were separated from the matrix residue by first boiling in nitric acid to clean off any residual matrix from the outer surface of the TRISO particles, and then washing the matrix residue and acid through a sieve with $500-\mu \mathrm{m}$-square holes. The washed and dried particles were then transferred to the IMGA hot cell for gamma analysis (Figure 1). The matrix residue was dried and burned at $750^{\circ} \mathrm{C}$ to remove carbon and oxidize metallic fission products not dissolved in the pre-burn leaches; boiling nitric acid was then used to leach the ash. Burn-leach (BL) of the particles was not performed because it was deemed unnecessary, given that low cesium release during safety testing indicated that no particles had failed $\mathrm{SiC}$. 

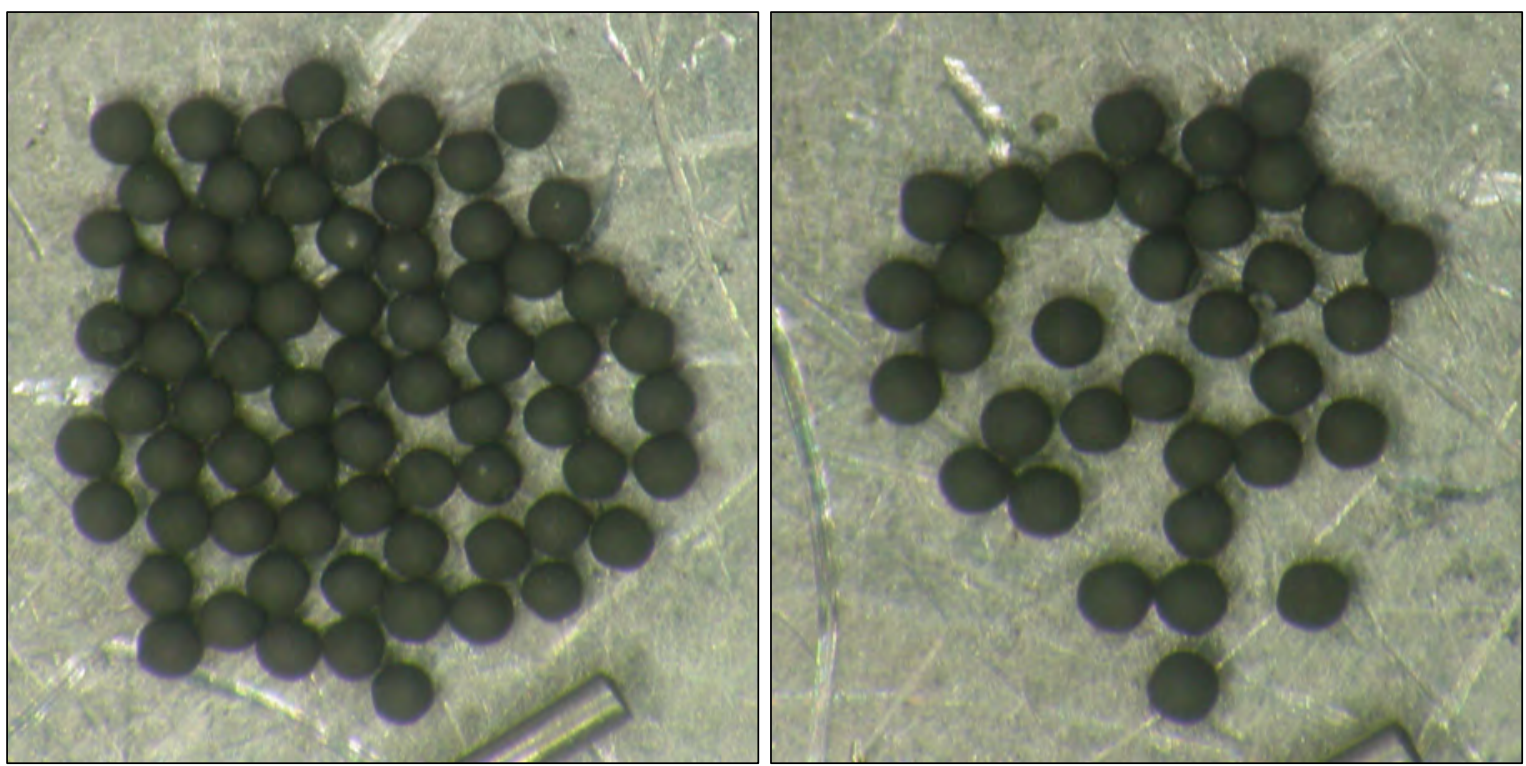

Figure 1. Particles deconsolidated and riffled for IMGA.

If cesium release during safety testing indicates the presence of particles with failed $\mathrm{SiC}$, an IMGA survey of all the TRISO-coated particles using a 100-120 sec counting time is usually performed to detect the low-cesium particles. However, no failed $\mathrm{SiC}$ was indicated during Compact 4-2-2 safety testing, therefore full IMGA survey was not performed. A random sample of 103 particles was gamma scanned for $6 \mathrm{~h}$ each to examine the average inventory of various detectable radioisotopes $\left({ }^{106} \mathrm{Ru},{ }^{110 \mathrm{~m}} \mathrm{Ag},{ }^{125} \mathrm{Sb}\right.$, ${ }^{134} \mathrm{Cs},{ }^{137} \mathrm{Cs},{ }^{144} \mathrm{Ce}$, and $\left.{ }^{154} \mathrm{Eu}\right)$.

After IMGA examination, particles were selected for microstructural analysis. Particles with high, moderate, and low silver release were sampled. Microstructural analysis included x-ray imaging and materialographic inspection by mechanical polishing followed by analysis using optical and scanning electron microscopes.

Three-dimensional microstructural analysis was achieved using a high-resolution x-ray tomography system specifically designed for imaging TRISO-coated particles. This system can image coating structure with resolution close to $1 \mu \mathrm{m}$, and has been used during AGR-1 fuel development to characterize and understand defect structures in unirradiated, as-fabricated particles in a manner not previously available. For AGR-1 PIE, a shielded container has been designed for mounting irradiated particles on the x-ray tomography stage. This shielded container allows single particles to be removed from the hot cell and transported to the tomography instrument for imaging. The shielding also reduces gamma radiation interference in the detector and electronics. Radiographic image sets using 3200 particle orientations were acquired to support high-resolution three-dimensional (3D) tomographic reconstruction of the irradiated particle internal microstructure.

Mechanical polishing to reveal particle cross sections was achieved by mounting particles in epoxy and grinding/polishing with a Buehler Minimet 1000. Vacuum back-potting was used to prevent damage to the internal structure and improve the quality of the final polished cross section. Kernels and coating layers were imaged using an optical microscope. Scanning electron microscopy (SEM) was performed on some samples to provide additional information. Secondary-electron image (SEI) and backscatteredelectron composition (BEC) modes were used to examine the structure and detect fission product clusters outside of the kernel, which were identified with Energy Dispersive Spectrometry (EDS). 


\section{FURNACE TESTING RESULTS}

[edited extract from earlier brief letter report, Hunn et al. 2014-1]

The overall temperature profile and time-dependent silver results are shown in Figure 2. The plotted results show the cumulative fraction of the Compact 4-2-2 calculated fission product inventory [Sterbentz 2013] that was collected on the deposition cups. However, compact gamma scanning prior to safety testing [Harp 2013] determined that $60 \%$ of the Compact $4-2-2$ calculated ${ }^{110 \mathrm{~m}} \mathrm{Ag}$ inventory was previously released during the AGR-1 irradiation test in the ATR, so the plotted fractions are lower than they would be if the measured values were evaluated relative to the actual available inventory.

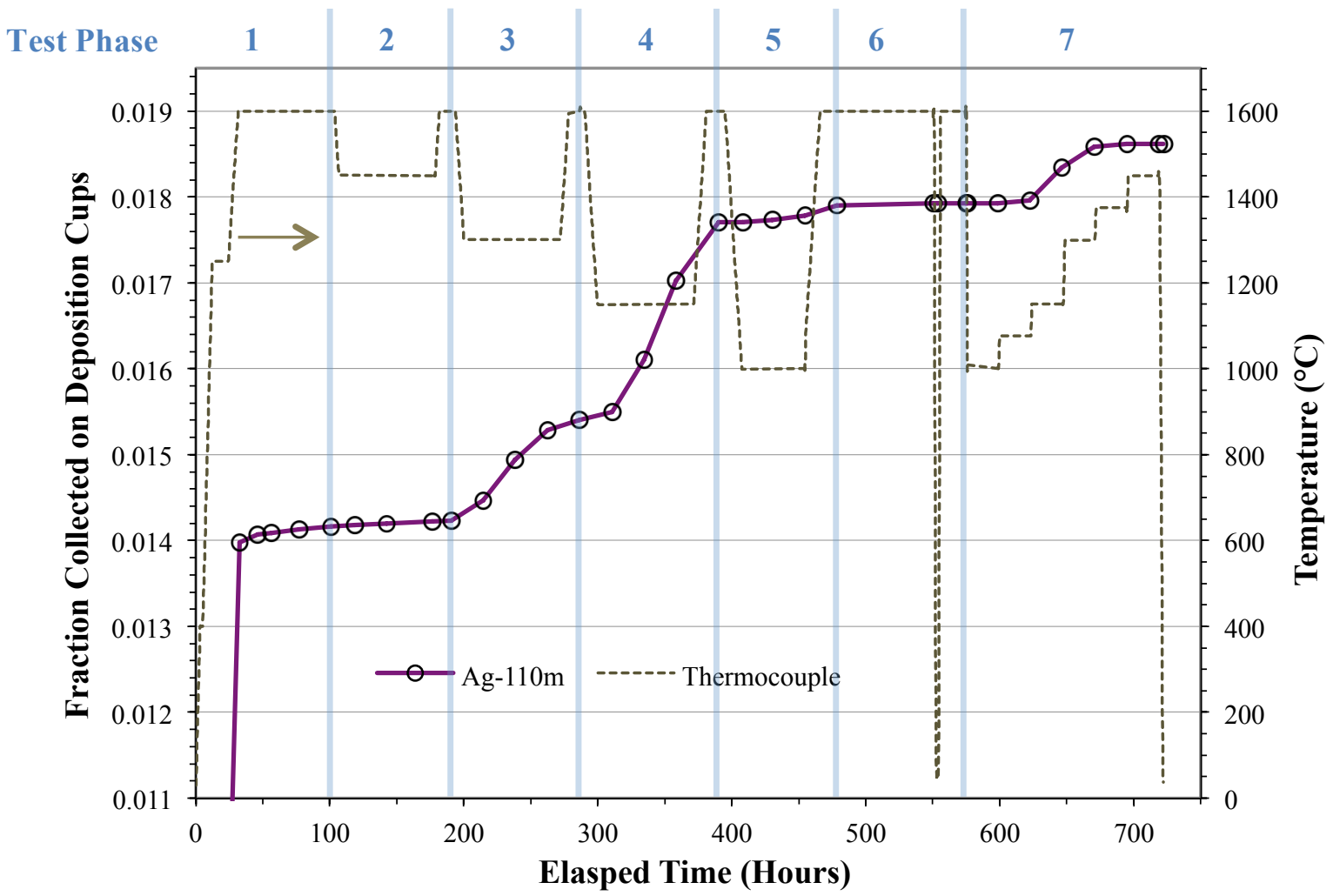

Figure 2. Collection of ${ }^{110 \mathrm{~m}} \mathrm{Ag}$ from Compact 4-2-2 during multiple-temperature safety testing. Data points show the end of each cup collection period, when resident cup was exchanged for a new cup.

The compact was initially taken to a maximum test temperature of $1600^{\circ} \mathrm{C}$ and held there for $72 \mathrm{~h}$. Based on results from previous $1600^{\circ} \mathrm{C}$ tests, this amount of time at $1600^{\circ} \mathrm{C}$ was expected to flush most of the silver out of the compact matrix and outer pyrolytic carbon layer (OPyC) and deposit it on the deposition cups. Figure 2 shows that $98.7 \%$ of the initial silver release in Phase 1 was detected within the first hour after reaching $1600^{\circ} \mathrm{C}$. Subsequent cups exchanged during this first $1600^{\circ} \mathrm{C}$ hold showed very little additional silver accumulation (only $1.3 \%$ of the total at that point). This agreed with the expectation that silver remaining in the matrix and $\mathrm{OPyC}$ due to release through intact $\mathrm{SiC}$ would be released by the initial 72 hour soak at $1600^{\circ} \mathrm{C}$. When the temperature was reduced to $1450^{\circ} \mathrm{C}$ in Phase 2, additional silver collection was negligible. Because the deposition cup collection efficiency at $1450^{\circ} \mathrm{C}$ was not specifically known and estimated to be $\sim 70 \%$ based on CCCTF historical data, the furnace was heated back up to $1600^{\circ} \mathrm{C}$ at the end of Phase 2, where collection efficiency is expected to be $>95 \%$, to try to ensure any exposed silver was collected on the last cup in that phase. However, silver accumulation remained negligible, indicating negligible silver was released from the compact at $1450^{\circ} \mathrm{C}$.

In Phase 3, the temperature was dropped to $1300^{\circ} \mathrm{C}$ and significant silver was collected on each cup exchanged during that phase. This was a surprising result, given that silver release had already flattened out at higher temperatures. In Phase 4, the process was repeated with an $1150^{\circ} \mathrm{C}$ hold. Again significant 
additional silver accumulated on the deposition cups (about twice what was detected during the $1300^{\circ} \mathrm{C}$ hold). The increased accumulation of silver during Phases 3 and 4, after the apparent depletion of silver from the matrix and OPyC during Phases 1 and 2, suggests that additional silver was released through intact $\mathrm{SiC}$ coatings. At the end of Phases 3 and 4, the furnace temperature was raised to $1600^{\circ} \mathrm{C}$, but there was no large increase in silver collection that would indicate that silver released through the $\mathrm{SiC}$ at 1150 and $1300^{\circ} \mathrm{C}$ was significantly held up in the $\mathrm{OPyC}$ or matrix, or trapped elsewhere in the furnace and released to the cup as the temperature was raised.

Figure 3 shows the average ${ }^{110 \mathrm{~m}} \mathrm{Ag}$ collection rate (fraction collected on each cup divided by the residence time). This shows how the silver collection rate rapidly dropped off after the first hour at $1600^{\circ} \mathrm{C}$ and stayed low through the remainder of Phases 1 and 2. At the beginning of Phase 3, the silver collection rate increased dramatically. The first Phase 3 cup only collected about half the silver as the second, but this was biased by the fact that the furnace was cooled slowly and was only at $1300^{\circ} \mathrm{C}$ for the latter $58 \%$ of the first collection period. (Collection periods during Phases 1-5 were $\sim 24$ hours each.) The fourth Phase 3 cup had a lower average collection rate than the others because the furnace was only at $1300^{\circ} \mathrm{C}$ for the first $42 \%$ of the fourth collection period. Very little silver was collected on the first Phase 4 cup, partially due to the slow cooldown limiting the dwell time at lower temperature, but also probably due to a slower migration of silver to the deposition cup at $1150^{\circ} \mathrm{C}$ resulting in a delay period before silver released from the particles started collecting on the cups. The average collection rate increased during the second and third collection periods at $1150^{\circ} \mathrm{C}$, eventually reaching a rate almost double that observed at $1300^{\circ} \mathrm{C}$. The fourth Phase 4 cup had a $56 \%$ lower average collection rate than the previous cup, but it was only at $1150^{\circ} \mathrm{C}$ for about $41 \%$ of the collection period, so this seems to indicate the silver release rate remained near its peak until the furnace was heated above $1150^{\circ} \mathrm{C}$ and the rate dropped to that observed at higher tempertures.

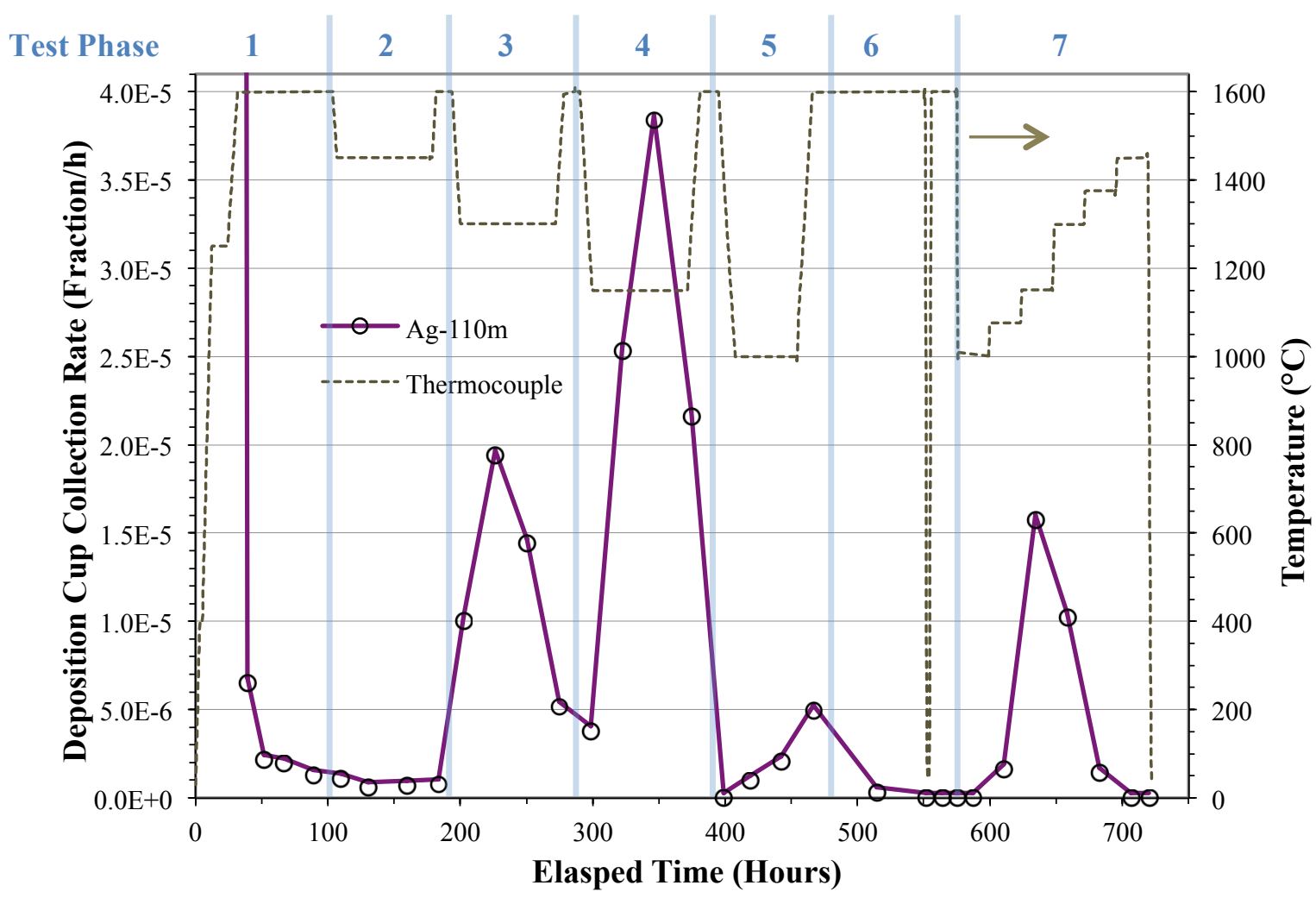

Figure 3. Collection of ${ }^{110 \mathrm{~m}} \mathrm{Ag}$ from Compact 4-2-2 during multiple-temperature safety testing. Data points show the middle of each cup collection period.

During the Phase 5 hold at $1000^{\circ} \mathrm{C}$, silver collection rate dropped below that observed at 1300 and $1150^{\circ} \mathrm{C}$, but not as low as observed at 1450 and $1600^{\circ} \mathrm{C}$. The rate continued to increase throughout 
Phase 5, again indicating a delay in the transport of silver to the deposition cups at the lower test temperatures; this is not surprising since the vapor pressure drops exponentially as the melting point $\left(962^{\circ} \mathrm{C}\right)$ is approached. The average collection rate at the end of Phase 5 was probably positively biased by the time spent in the temperature range between 1150 and $1300^{\circ} \mathrm{C}$ during the ramp back to $1600^{\circ} \mathrm{C}$.

Phase 6 involved another 72 -hour hold at $1600^{\circ} \mathrm{C}$, during which silver release continued to be negligible, followed by a quick thermal cycle to room temperature and back. No measurable silver release was detected after this thermal cycle. In an attempt to separate the steady state release observed in the earlier test phases from possible transient effects, the ramp rate for this thermal cycle was increased in order to reduce the dwell time at temperatures around 1150 and $1300^{\circ} \mathrm{C}$. This thermal cycle test was performed to explore the conditions that led to secondary silver release in earlier tests (e.g. the Compact 3-3-2 safety test shown in Figure 4). In those earlier tests, the ramp rate back to temperature was almost ten times slower; so it appears that the silver release in those earlier test may have also occurred when the compacts were at temperatures around 1150 and $1300^{\circ} \mathrm{C}$.

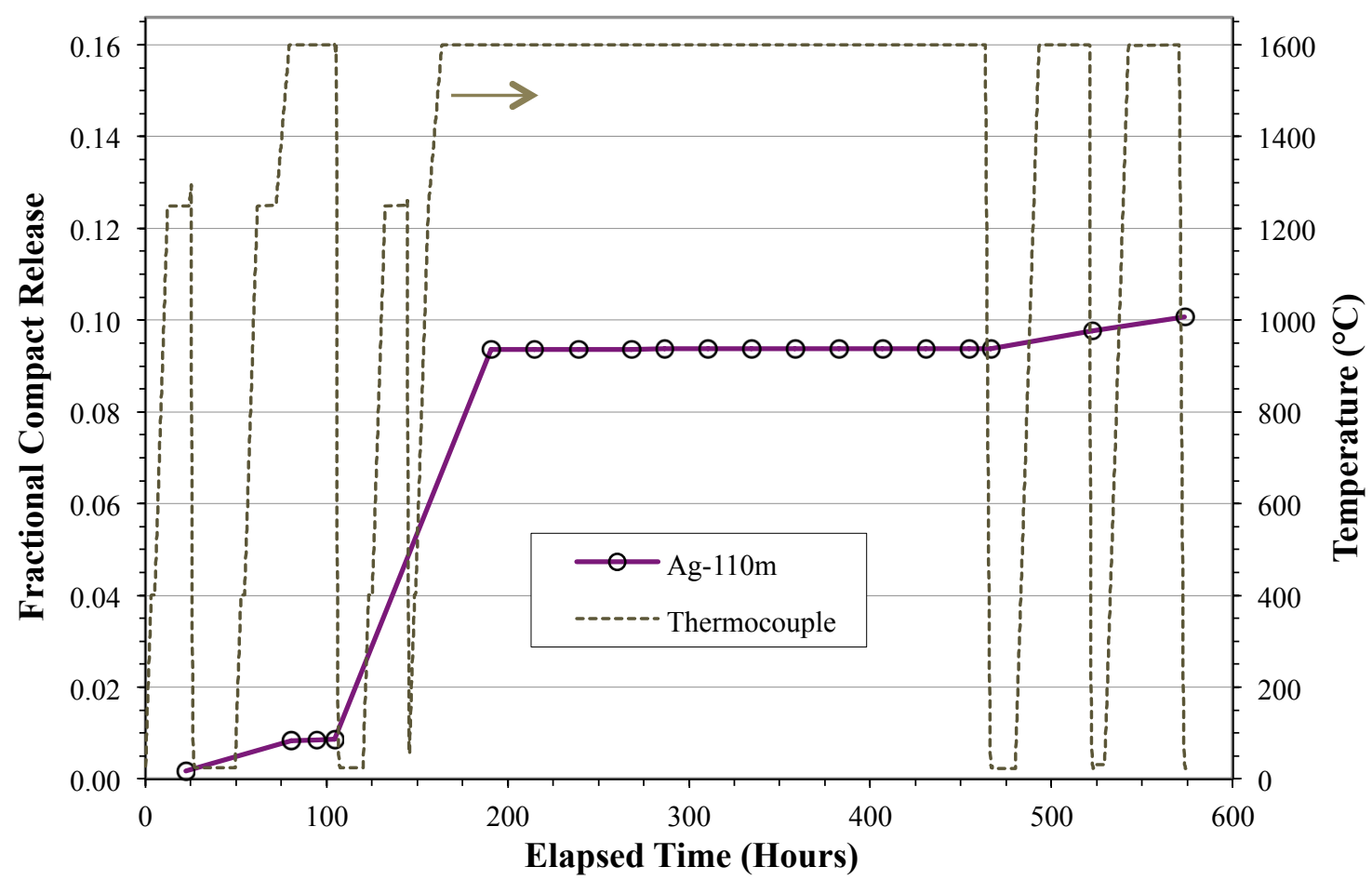

Figure 4. Collection of ${ }^{110 \mathrm{~m}} \mathrm{Ag}$ from Compact 3-3-2 during $1600^{\circ} \mathrm{C}$ safety testing that was preceded by unplanned thermal cycling (due to issues with power supply) and followed by planned thermal cycling. Additional silver was released each time the temperature was cycled [Hunn, Morris, and Baldwin 2012].

In Phase 7, the temperature was dropped to $1000^{\circ} \mathrm{C}$ using the same rapid ramp rate, and then stepped back up to $1450^{\circ} \mathrm{C}$ in 24 -hour intervals. Neglible silver was deposited on the cups at 1000 and $1075^{\circ} \mathrm{C}$, silver collection rate peaked at $1150^{\circ} \mathrm{C}$ and remained high at $1300^{\circ} \mathrm{C}$, deposition dropped off again at $1375^{\circ} \mathrm{C}$, and was negligible at $1450^{\circ} \mathrm{C}$. The Phase 7 releases agreed with the earlier results and further refined the temperature range at which silver release appeared to be active.

Figure 5 shows the cumulative fractional deposition of the other measurable radioisotopes over the first six phases. Cesium release was very low; only ${ }^{134} \mathrm{Cs}$ is reported because ${ }^{137} \mathrm{Cs}$ activities were below the detection limit for this longer-lived isotope, which has higher background interference from several decades of accumulated hot cell contamination. The low cesium collection, even at $1600^{\circ} \mathrm{C}$, indicates that no particles experienced $\mathrm{SiC}$ failure. Europium and strontium results are interesting because they show trends that are nearly opposite to the silver data trends in Figure 2. Europium and strontium collection rates were the highest at $1600^{\circ} \mathrm{C}$, moderate at $1450^{\circ} \mathrm{C}$, and essentially negligible at the lower 
temperatures. This does not necessarily indicate europium and strontium were being released through intact $\mathrm{SiC}$ at $1600^{\circ} \mathrm{C}$, but more likely indicates a temperature-dependent reduction in the transport rate of europium and strontium from the matrix and $\mathrm{OPyC}$, through the graphite holder, and to the deposition cups. Results during Phase 7 were similar (Figure 6), with no measurable collection of europium and strontium until $1450^{\circ}$ was reached.

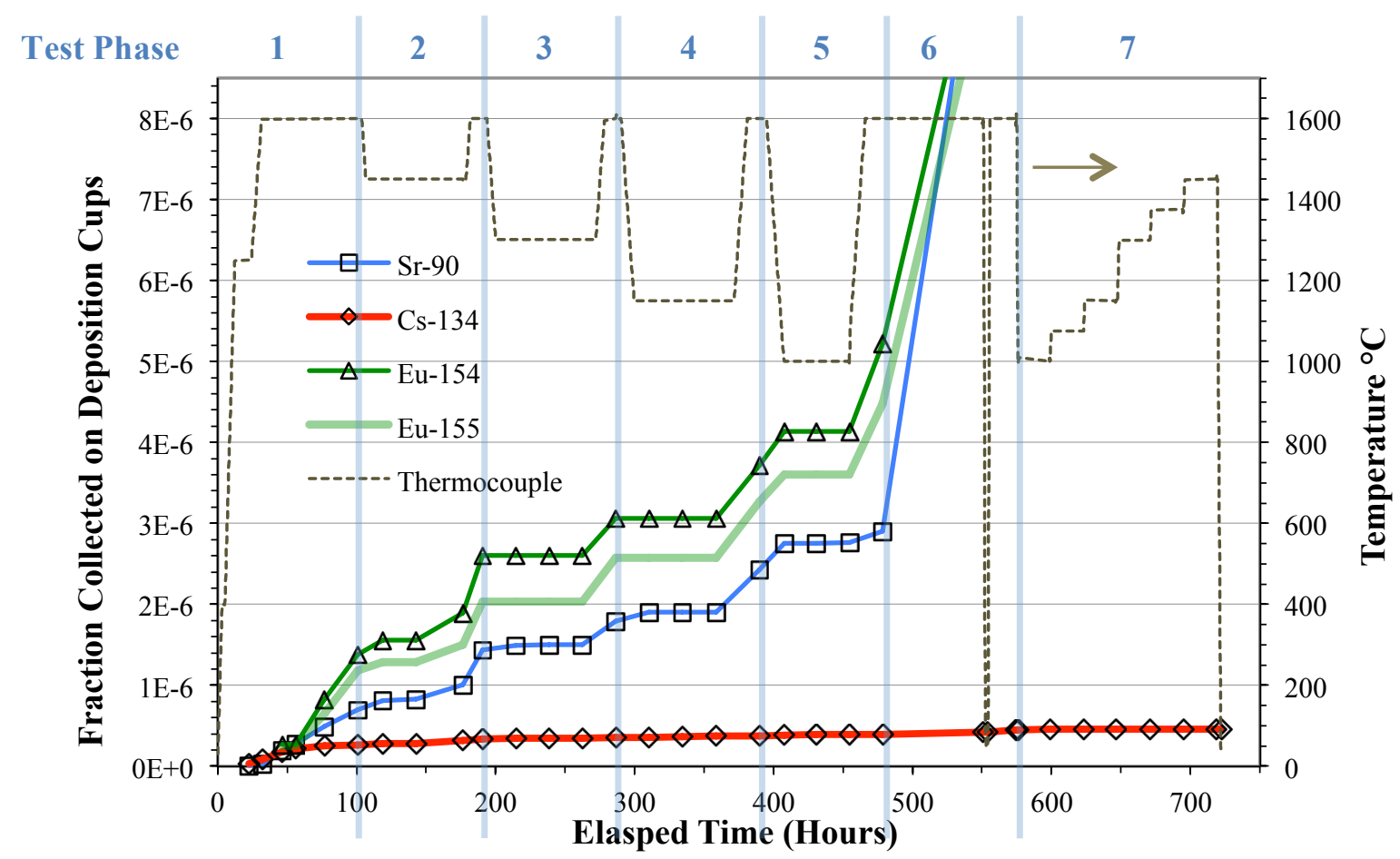

Figure 5. Collection of other radioisotopes from Compact 4-2-2. Data points show the end of each cup collection period.

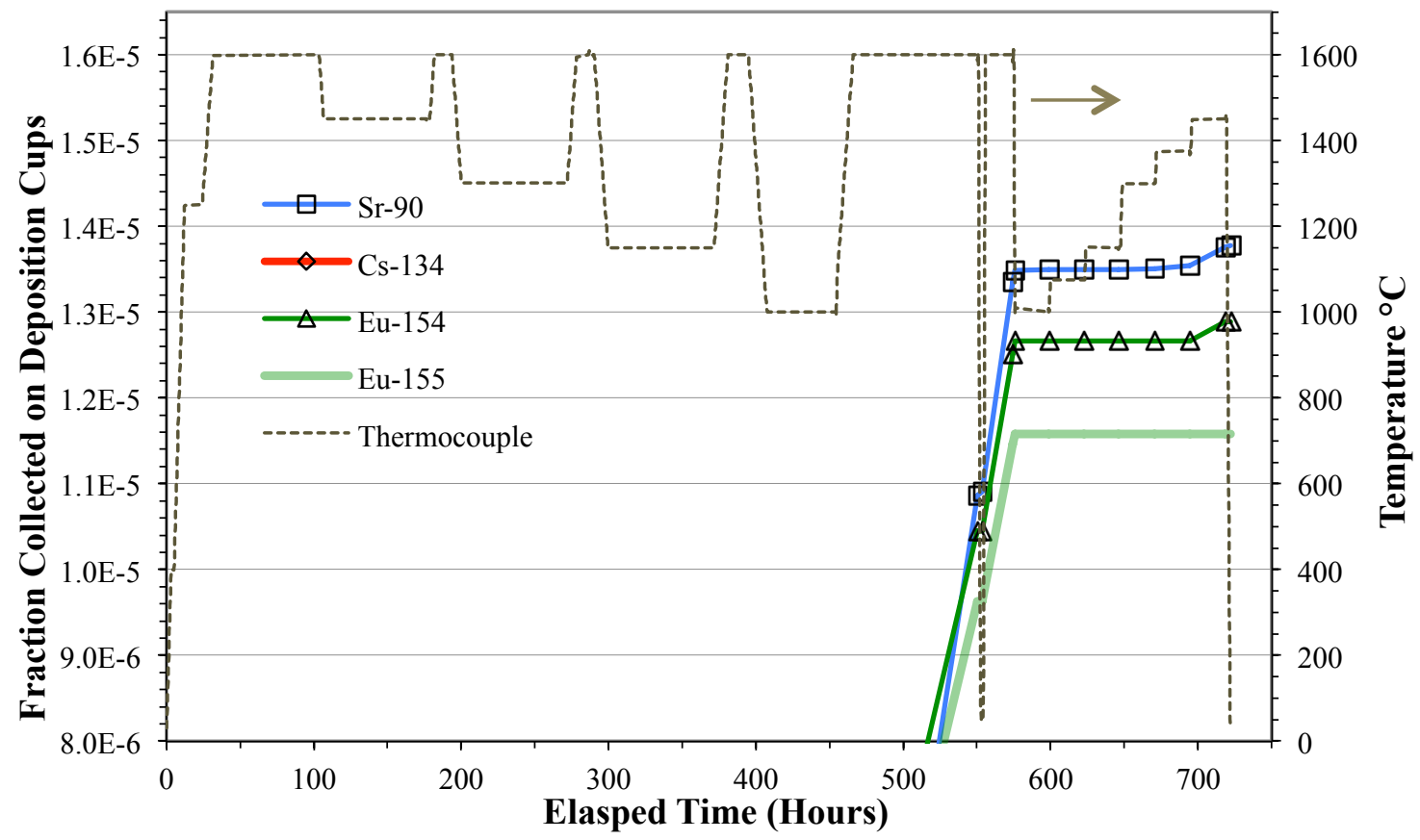

Figure 6. Collection of other radioisotopes from Compact 4-2-2. Data points show the end of each cup collection period. 
At the end of the furnace test, the cumulative release of various radioisotopes from Compact 4-2-2, in terms of the fraction of the fission product inventory calculated to have been generated by the AGR-1 irradiation test [Sterbentz 2013], was determined by summing the activity measured on all the cups plus what was detected on the other CCCTF internals (graphite holder, tantalum liner, and tantalum gas inlet line). Table 1 lists these total cumulative releases along with the fraction detected on each furnace component. The europium and strontium distributions exhibit the expected slow release of these elements from the graphite holder (europium and strontium inventory remaining in the compact matrix and OPyC were even higher than what was held in the graphite holder). Because the cesium release was very low, cesium distributions may be more indicative of contributions from hot cell contamination than reflective of cesium transport between these components. However, silver distribution was atypical compared to other CCCTF tests, where close to $100 \%$ of released silver was usually collected on the deposition cups. This anomalous silver distribution may have been partially due to the lower test temperatures (the furnace was designed to be operated from $1400-1800^{\circ} \mathrm{C}$ and the deposition cup is located for best collection at these temperatures). However, an unusually large fraction $(69.1 \%)$ of the total detected ${ }^{110 \mathrm{~m}} \mathrm{Ag}$ was located at the top of the furnace on the tantalum gas inlet line (above the water-cooled deposition cup). The mechanism by which the silver bypassed the deposition cups to be deposited on the gas line is thought to be related to poor thermal contact between the deposition cup and cold finger resulting in higher-than-intended cup temperatures. It was determined that the deposition cups used in this test had an inside radius that contacted the outer diameter of the cold finger and produced a gap between the bottom of the cold finger and the bottom of the cup. Tests are underway to measure the deposition cup temperature under various conditions to better understand this problem. Whether this anomalous silver distribution may possibly impact the interpretation of the observed thermal-dependent and timedependent collection of ${ }^{110 \mathrm{~m}} \mathrm{Ag}$ on the deposition cups is not known. A significant concern is the possibility that silver collected on the cups at 1150 and $1300^{\circ} \mathrm{C}$ may have come from the top of the furnace rather than from the compact; however, this seems unlikely because it would involve silver moving from a cooler zone to a warmer one. The fact that silver was not collected on the cups as the temperature was raised from the lower temperatures to $1600^{\circ} \mathrm{C}$, suggests that silver migration from furnace components to the deposition cups was not an issue.

Table 1. Cumulative releases from Compact 4-2-2 of radioactive isotopes detected on the CCCTF furnace internals at the end of the test, and the final distribution of these radioisotopes on the various components

\begin{tabular}{|c||c|c|c|c|c|}
\hline Isotope & ${ }^{\mathbf{9}} \mathbf{S r}$ & ${ }^{{ }^{134} \mathbf{C s}}$ & ${ }^{{ }^{110 m} \mathbf{A g}}$ & ${ }^{{ }^{154} \mathbf{E u}}$ & ${ }^{155} \mathbf{E u}$ \\
\hline $\begin{array}{c}\text { Fraction of compact } \\
\text { inventory released }\end{array}$ & $2.97 \mathrm{E}-4$ & $8.78 \mathrm{E}-7$ & $6.02 \mathrm{E}-2$ & $4.76 \mathrm{E}-4$ & $5.52 \mathrm{E}-4$ \\
\hline $\begin{array}{c}\text { Fraction on } \\
\text { deposition cups }\end{array}$ & $4.6 \%$ & $52.8 \%$ & $30.9 \%$ & $2.7 \%$ & $2.1 \%$ \\
$\begin{array}{c}\text { Fraction on } \\
\text { tantalum parts }\end{array}$ & $15.2 \%$ & $22.6 \%$ & $69.1 \%$ & $12.7 \%$ & $13.1 \%$ \\
\hline $\begin{array}{c}\text { Fraction on } \\
\text { graphite holder }\end{array}$ & $80.1 \%$ & $24.6 \%$ & $0 \%$ & $84.6 \%$ & $84.8 \%$ \\
\hline
\end{tabular}




\section{DLBL RESULTS}

Table 2 through Table 4 summarize the results of the DLBL analyses. These results indicate how much of each isotope not contained within intact $\mathrm{SiC}$ was detected in the compact before the burn step, and how much remained in the matrix after the burn step (which oxidizes exposed carbon and most of the exposed metallic elements not previously leached). To reduce analysis cost, post-burn leaching of the particles was not performed due to low expectation of contributions from the particle burn-leach contributing significantly to the totals (especially given that safety testing indicated that there were no particles with failed $\mathrm{SiC}$ ). Results are presented in terms of the compact inventory fraction, where $2.42 \mathrm{E}-4$ would be equivalent to the inventory in a single particle. The compact inventory fraction was determined by dividing the measured amount of each isotope by the amount that was calculated to be in the fuel as a result of the three-year irradiation, after accounting for subsequent radioactive decay and assuming no significant fission product release occurred during irradiation (these calculated values can be found in [Sterbentz 2013]). With the exception of notable silver release from the compact during irradiation (as discussed in the previous section), the assumption of insignificant radioisotope release for the determination of compact inventory fraction is reasonable based on gamma survey of the AGR-1 capsule components [Demkowicz et al. 2013]. The equivalent particle inventory in Table 3 and Table 4 was determined from the compact inventory fraction by multiplying by the average number of particles in a Capsule 4 compact (4126) [Hunn, Savage, and Silva 2012].

Table 3 includes data from as-irradiated Compact 4-4-2 for comparison to the uranium and plutonium data obtained after furnace testing of Compact 4-2-2. Detection of uranium during deconsolidation and pre-burn leaching is a good indicator for exposed kernels due to failed TRISO layers. The low uranium releases reported in Table 3 indicate that no failed TRISO was present in these compacts, in good agreement with the irradiation and safety test results, where krypton releases were negligible. The total exposed compact fractions for the reported isotopes of uranium and plutonium were fairly similar for these two compacts, and significantly higher than would be expected from the $<2 \mathrm{E}-7$ average exposed uranium fraction measured in pre-irradiated AGR-1 Variant 3 compacts [Hunn et al. 2013-1, page 11]. This indicates some release of these elements through intact SiC. In Compact 4-2-2, a greater fraction of these exposed actinides were bound up in the matrix until after the burn step, possibly due to the effect of heating in the CCCTF.

Exposed fission product inventories reported in Table 4 are consistent with what has been observed in other safety tests that did not involve particles with failed $\mathrm{SiC}$, such as Compact 5-3-3 after $1600^{\circ} \mathrm{C}$ safety testing [Hunn et al. 2014-2] and Compact 4-4-3 after $1700^{\circ} \mathrm{C}$ safety testing [Hunn et al. 2014-3]. The levels of exposed silver and palladium remaining in Compact 4-2-2 were found to be much lower than those observed in as-irradiated compacts [Demkowicz et al. 2014]; this agrees with the conclusion that silver and palladium were readily diffusing out of the matrix when the compact was heated in the CCCTF. Significant fractions of strontium and europium also migrated out of the compact during the heating test (Figure 6), but not quite as readily as silver. Table 2 shows that the majority of strontium and europium was retained in the compact, and most of what escaped was trapped in the graphite holder, as discussed in the previous section (Table 1).

Table 2. Distribution of strontium, europium, and cesium outside of $\mathrm{SiC}$ after safety testing

\begin{tabular}{|c||c|c|c|c|}
\hline Isotope & ${ }^{90} \mathbf{S r}$ & ${ }^{154} \mathbf{E u}$ & ${ }^{155} \mathbf{E u}$ & ${ }^{134} \mathbf{C s}$ \\
\hline \hline Fraction of compact inventory detected by DLBL & $4.96 \mathrm{E}-4$ & $1.32 \mathrm{E}-3$ & $1.51 \mathrm{E}-3$ & $1.92 \mathrm{E}-5$ \\
\hline Fraction of compact inventory released in CCCTF & $2.97 \mathrm{E}-4$ & $4.76 \mathrm{E}-4$ & $5.52 \mathrm{E}-4$ & $8.78 \mathrm{E}-7$ \\
\hline Fraction outside SiC that was retained in compact & $62.5 \%$ & $73.5 \%$ & $73.3 \%$ & $95.6 \%$ \\
\hline Fraction outside $\mathrm{SiC}$ that was released from compact & $37.5 \%$ & $26.5 \%$ & $26.7 \%$ & $4.4 \%$ \\
\hline
\end{tabular}


ORNL/TM-2015/033-R0

Table 3. Exposed compact inventory fractions for $\mathrm{U}$ and $\mathrm{Pu}$ detected by $\mathrm{LBL}$ for furnace-tested Compact 4-2-2 and as-irradiated Compact 4-4-2

\begin{tabular}{|c|c|c|c|c|c|c|c|c|c|c|}
\hline & \multicolumn{5}{|c|}{ Compact 4-2-2 } & \multicolumn{5}{|c|}{ Compact 4-4-2 } \\
\hline & ${ }^{235} \mathrm{U}$ & ${ }^{236} \mathbf{U}$ & ${ }^{238} \mathbf{U}$ & ${ }^{239} \mathrm{Pu}$ & ${ }^{240} \mathrm{Pu}$ & ${ }^{235} \mathbf{U}$ & ${ }^{236} \mathbf{U}$ & ${ }^{238} \mathbf{U}$ & ${ }^{239} \mathrm{Pu}$ & ${ }^{240} \mathrm{Pu}$ \\
\hline $\begin{array}{l}\text { Possible background } \\
\text { contamination levels }\end{array}$ & $\begin{array}{l}\text { up to } \\
2 \mathrm{E}-6\end{array}$ & $\begin{array}{l}\text { up to } \\
5 \mathrm{E}-7\end{array}$ & $\begin{array}{l}\text { up to } \\
3 \mathrm{E}-6\end{array}$ & $\begin{array}{l}\text { up to } \\
2 \mathrm{E}-6\end{array}$ & $\begin{array}{l}\text { up to } \\
3 \mathrm{E}-6\end{array}$ & $\begin{array}{l}\text { up to } \\
2 \mathrm{E}-6\end{array}$ & $\begin{array}{l}\text { up to } \\
5 \mathrm{E}-7\end{array}$ & $\begin{array}{l}\text { up to } \\
3 \mathrm{E}-6\end{array}$ & $\begin{array}{l}\text { up to } \\
2 \mathrm{E}-6\end{array}$ & $\begin{array}{l}\text { up to } \\
3 \mathrm{E}-6\end{array}$ \\
\hline $\begin{array}{l}\text { Deconsolidation followed by } \\
\text { Pre-burn leach } 1\end{array}$ & $3.43 \mathrm{E}-6$ & $2.13 \mathrm{E}-6$ & $4.14 \mathrm{E}-6$ & $4.36 \mathrm{E}-6$ & $6.76 \mathrm{E}-6$ & $2.26 \mathrm{E}-5$ & $1.13 \mathrm{E}-5$ & $1.85 \mathrm{E}-5$ & $1.17 \mathrm{E}-5$ & $1.29 \mathrm{E}-5$ \\
\hline Pre-burn leach 2 & $7.57 \mathrm{E}-7$ & $4.26 \mathrm{E}-7$ & $9.40 \mathrm{E}-7$ & $1.58 \mathrm{E}-6$ & $2.37 \mathrm{E}-6$ & $4.11 \mathrm{E}-7$ & $6.01 \mathrm{E}-7$ & $3.59 \mathrm{E}-6$ & $1.53 \mathrm{E}-6$ & 2.09E-6 \\
\hline Post-burn particle leach $1^{\text {(a) }}$ & & & & & & $6.40 \mathrm{E}-6$ & $1.19 \mathrm{E}-6$ & $3.49 \mathrm{E}-6$ & $2.66 \mathrm{E}-6$ & $3.29 \mathrm{E}-6$ \\
\hline Post-burn particle leach $2^{(a)}$ & & & & & & $5.64 \mathrm{E}-7$ & $<1.01 \mathrm{E}-7$ & $8.68 \mathrm{E}-7$ & 7.17E-7 & $9.46 \mathrm{E}-7$ \\
\hline Post-burn matrix leach 1 & $1.84 \mathrm{E}-5$ & $3.53 \mathrm{E}-5$ & $4.45 \mathrm{E}-5$ & $3.02 \mathrm{E}-5$ & $3.64 \mathrm{E}-5$ & $1.03 \mathrm{E}-5$ & $2.07 \mathrm{E}-6$ & $3.46 \mathrm{E}-5$ & $1.79 \mathrm{E}-5$ & $2.68 \mathrm{E}-5$ \\
\hline Post-burn matrix leach 2 & $7.73 \mathrm{E}-7$ & $1.11 \mathrm{E}-6$ & $3.33 \mathrm{E}-6$ & $1.88 \mathrm{E}-6$ & $2.25 \mathrm{E}-6$ & $6.09 \mathrm{E}-7$ & $1.20 \mathrm{E}-7$ & $2.23 \mathrm{E}-6$ & $1.50 \mathrm{E}-6$ & $2.04 \mathrm{E}-6$ \\
\hline Total & $2.33 \mathrm{E}-5$ & $3.90 \mathrm{E}-5$ & $5.29 \mathrm{E}-5$ & $3.80 \mathrm{E}-5$ & $4.77 \mathrm{E}-5$ & $4.09 \mathrm{E}-5$ & $1.53 \mathrm{E}-5$ & $6.33 \mathrm{E}-5$ & $3.60 \mathrm{E}-5$ & $4.80 \mathrm{E}-5$ \\
\hline Equivalent particle inventory & 0.10 & 0.16 & 0.22 & 0.16 & 0.20 & 0.17 & 0.06 & 0.26 & 0.15 & 0.20 \\
\hline $\begin{array}{l}\text { Molar inventory } \\
\text { at EOL + } 1 \text { day }\end{array}$ & $3.44 \mathrm{E}-9$ & 3.91E-9 & $1.53 \mathrm{E}-7$ & $1.39 \mathrm{E}-9$ & $8.82 \mathrm{E}-10$ & $5.99 \mathrm{E}-9$ & $1.52 \mathrm{E}-9$ & $1.83 \mathrm{E}-7$ & $1.39 \mathrm{E}-9$ & $9.02 \mathrm{E}-10$ \\
\hline
\end{tabular}

Values that primarily contributed to the total for each isotope are highlighted. Numbers in gray are low compared to possible background.

(a) Post-burn particle leach was not performed on Compact 4-2-2; post-burn particle leach data for Compact 4-4-2 was multiplied by $4126 / 4003$ to account for 123 particles held out of the sample after IMGA analysis. 
ORNL/TM-2015/033-R0

Table 4. Compact inventory fractions of important gamma emitting fission products detected by LBL of AGR-1 irradiated Compact 4-2-2 (analyzed by gamma spectrometric method)

\begin{tabular}{|c|c|c|c|c|c|c|c|c|c|}
\hline Sample ID & ${ }^{90} \mathbf{S r}^{(b)}$ & ${ }^{105} \mathrm{Pd}$ & ${ }^{106} \mathbf{R u}$ & ${ }^{110 m} \mathrm{Ag}$ & ${ }^{134} \mathrm{Cs}$ & ${ }^{137} \mathrm{Cs}$ & ${ }^{144} \mathrm{Ce}$ & ${ }^{154} \mathbf{E u}$ & ${ }^{155} \mathbf{E u}$ \\
\hline $\begin{array}{l}\text { Possible background } \\
\text { contamination levels }\end{array}$ & $\begin{array}{l}\text { up to } \\
5 \mathrm{E}-7\end{array}$ & $\begin{array}{l}\text { up to } \\
3 \mathrm{E}-4\end{array}$ & $\begin{array}{l}\text { up to } \\
4 \mathrm{E}-7\end{array}$ & - (c) & $\begin{array}{l}\text { up to } \\
2 \mathrm{E}-7\end{array}$ & $\begin{array}{l}\text { up to } \\
6 \mathrm{E}-7\end{array}$ & $\begin{array}{l}\text { up to } \\
5 \mathrm{E}-7\end{array}$ & $\begin{array}{l}\text { up to } \\
3 \mathrm{E}-6\end{array}$ & $\begin{array}{l}\text { up to } \\
2 \mathrm{E}-6\end{array}$ \\
\hline $\begin{array}{l}\text { Deconsolidation followed by } \\
\text { Pre-burn leach } 1\end{array}$ & $3.41 \mathrm{E}-4$ & $<2.95 \mathrm{E}-5$ & $3.37 \mathrm{E}-6$ & $<6.45 \mathrm{E}-4$ & $3.49 \mathrm{E}-7$ & $1.02 \mathrm{E}-6$ & $6.46 \mathrm{E}-6$ & $2.43 \mathrm{E}-4$ & $2.84 \mathrm{E}-4$ \\
\hline Pre-burn leach 2 & $3.43 \mathrm{E}-5$ & $<1.98 \mathrm{E}-5$ & $<1.10 \mathrm{E}-6$ & $<1.43 \mathrm{E}-4$ & $<5.84 \mathrm{E}-8$ & $2.30 \mathrm{E}-7$ & $2.54 \mathrm{E}-6$ & $6.59 \mathrm{E}-5$ & $7.41 \mathrm{E}-5$ \\
\hline \multicolumn{10}{|l|}{ Post-burn particle leach $1^{(\mathrm{a})}$} \\
\hline \multicolumn{10}{|l|}{ Post-burn particle leach $2^{(\mathrm{a})}$} \\
\hline Post-burn matrix leach 1 & $5.59 \mathrm{E}-5$ & $2.07 \mathrm{E}-5$ & $9.51 \mathrm{E}-6$ & $<8.92 \mathrm{E}-4$ & $1.82 \mathrm{E}-5$ & $2.06 \mathrm{E}-5$ & $3.52 \mathrm{E}-5$ & $9.97 \mathrm{E}-4$ & $1.14 \mathrm{E}-3$ \\
\hline Post-burn matrix leach 2 & $6.53 \mathrm{E}-5$ & $<1.97 \mathrm{E}-5$ & $<9.64 \mathrm{E}-7$ & $<1.54 \mathrm{E}-4$ & $6.38 \mathrm{E}-7$ & $1.38 \mathrm{E}-6$ & $1.04 \mathrm{E}-6$ & $1.36 \mathrm{E}-5$ & $1.53 \mathrm{E}-5$ \\
\hline Total & $4.96 \mathrm{E}-4$ & $2.07 \mathrm{E}-5$ & $1.29 \mathrm{E}-5$ & $-(d)$ & $1.92 \mathrm{E}-5$ & $2.33 \mathrm{E}-5$ & $4.52 \mathrm{E}-5$ & $1.32 \mathrm{E}-3$ & $1.51 \mathrm{E}-3$ \\
\hline Equivalent particle inventory & 2.0 & 0.09 & 0.05 & $-(d)$ & 0.08 & 0.10 & 0.2 & 5.4 & 6.2 \\
\hline Molar inventory at EOL +1 day & $1.56 \mathrm{E}-8$ & $2.00 \mathrm{E}-10$ & $5.39 \mathrm{E}-11$ & $-(d)$ & $5.89 \mathrm{E}-11$ & $8.98 \mathrm{E}-10$ & $5.93 \mathrm{E}-10$ & $5.70 \mathrm{E}-10$ & $2.62 \mathrm{E}-10$ \\
\hline
\end{tabular}

A less than symbol $(<)$ indicates concentration was below the minimum detectable limit, these values are not included in the totals.

Values that primarily contributed to the total for each isotope are highlighted. Numbers in gray are low compared to possible background.

(a) Post-burn particle leach was not performed on Compact 4-2-2.

(b) The ${ }^{90} \mathrm{Sr}$ was measured by chemical separation and beta analysis.

(c) Possible background contamination levels for ${ }^{110 \mathrm{~m}} \mathrm{Ag}$ were below minimum detectable limit.

(d) No leach solutions had detectable levels of ${ }^{110 \mathrm{~m}} \mathrm{Ag}$. 


\section{IMGA RESULTS}

A randomly-selected (RS) sample of 103 particles from Compact 4-2-2 was loaded into individual vials and subjected to 6-hour gamma scanning to obtain a quantitative analysis of several key radioisotopes. By handling particles in separate vials, the individual identity of each particle was maintained throughout the remainder of the PIE. Table 5 is a summary of the results. All activities are decay-corrected to one day after the end of irradiation (11/07/2009 at 1200 GMT). The average measured inventories can be compared to the total inventories predicted by the physics calculations for an average particle in each compact (also provided in the table); values in parentheses are the ratios of the average measured inventories to the average calculated inventories $(\mathrm{M} / \mathrm{C})$. The range in average activity for ${ }^{110 \mathrm{~m}} \mathrm{Ag}$ was calculated by summing the particles with undetectable ${ }^{110 \mathrm{~m}} \mathrm{Ag}$ as containing either zero silver or as high as the detection limit. There were 64 particles with silver inventory below the detection limit, which ranged from $1.02-1.64 \mathrm{E} 4 \mathrm{~Bq} /$ particle (i.e., $21-34 \%$ of the calculated inventory). The uncertainty and broad range in the measured silver inventory (between one quarter and one half of the expected inventory), is a function of the measurement being made almost seven ${ }^{110 \mathrm{~m}} \mathrm{Ag}$ half-lives after the end of irradiation. The standard deviation is given for both the raw measured activities and the inventories after adjusting for particle-to-particle variation in fissionable material and burn-up using the measured ${ }^{137} \mathrm{Cs}$ activity; this standard approach for refining IMGA results is described elsewhere [Hunn et al. 2013-1]. Note that the measured distributions are tighter after making this refinement, which is also used in the histograms in Figure 7-Figure 9.

Table 5. Radioactive isotopes detected in particles from Compact 4-2-2

\begin{tabular}{|c||cc|c|c|c|c|c|c|}
\hline \multicolumn{1}{|c||}{} & \multicolumn{6}{c|}{ Activity of various gamma-emitting isotopes in Bq/particle } \\
\cline { 2 - 9 } & ${ }^{\mathbf{1 0 6}} \mathbf{R u}$ & ${ }^{\mathbf{1 1 0}} \mathbf{A g}$ & ${ }^{\mathbf{1 2 5}} \mathbf{S b}$ & ${ }^{134} \mathbf{C s}$ & ${ }^{\mathbf{1 3 7}} \mathbf{C s}$ & ${ }^{144} \mathbf{C e}$ & ${ }^{\mathbf{1 5 4}} \mathbf{E u}$ \\
\hline $\begin{array}{c}\text { Calculated inventory }{ }^{\mathrm{a}} \text { for an } \\
\text { average particle from 4-2-2 }\end{array}$ & $1.32 \mathrm{E} 7$ & $4.79 \mathrm{E} 4$ & $3.11 \mathrm{E} 5$ & $4.77 \mathrm{E} 6$ & $4.11 \mathrm{E} 6$ & $5.39 \mathrm{E} 7$ & $1.61 \mathrm{E} 5$ \\
\hline $\begin{array}{c}\text { Average measured inventory } \\
\text { of 103 random particles }\end{array}$ & $\begin{array}{c}1.33 \mathrm{E} 7 \\
(1.01)\end{array}$ & $\begin{array}{c}1.2-2.3 \mathrm{E} 4 \\
(0.25-0.48)\end{array}$ & $\begin{array}{c}2.16 \mathrm{E} 5 \\
(0.70)\end{array}$ & $\begin{array}{c}4.66 \mathrm{E} 6 \\
(0.98)\end{array}$ & $\begin{array}{c}4.04 \mathrm{E} 6 \\
(0.98)\end{array}$ & $\begin{array}{c}5.71 \mathrm{E} 7 \\
(1.06)\end{array}$ & $\begin{array}{c}1.29 \mathrm{E} 5 \\
(0.80)\end{array}$ \\
\hline $\begin{array}{c}\text { Percent standard deviation in } \\
\text { average measured inventory }\end{array}$ & 7.52 & & 6.67 & 8.48 & 6.79 & 6.00 & 7.13 \\
\hline $\begin{array}{c}\text { Percent standard deviation in } \\
\text { average measured inventory } \\
\text { ratioed against }{ }^{137} \text { Cs content }\end{array}$ & 3.82 & & 2.43 & 3.47 & & 2.44 & 1.63 \\
\hline
\end{tabular}

${ }^{a}$ Inventories one day after irradiation from AGR-1 physics calculations [Sterbentz 2013].

${ }^{\mathrm{b}}$ Values in parentheses are the $\mathrm{M} / \mathrm{C}$ ratios; highlighted cells indicate a measurable isotopic release.

In the randomly-selected particles analyzed by IMGA, ${ }^{110 \mathrm{~m}} \mathrm{Ag}$ was the only isotope whose inventory was measurably below the calculated value due to release through intact $\mathrm{SiC}$. The measured to calculated ratios for ${ }^{125} \mathrm{Sb}$ and ${ }^{154} \mathrm{Eu}$ were uniformly low, but this was due to a positive bias in the calculated inventories and does not represent measurable loss of these isotopes from the particles [Harp 2013]. The average activities for ${ }^{106} \mathrm{Ru},{ }^{134} \mathrm{Cs},{ }^{137} \mathrm{Cs}$, and ${ }^{144} \mathrm{Ce}$ in the randomly-selected particles were close to the calculated values (within the uncertainty in the analysis). 


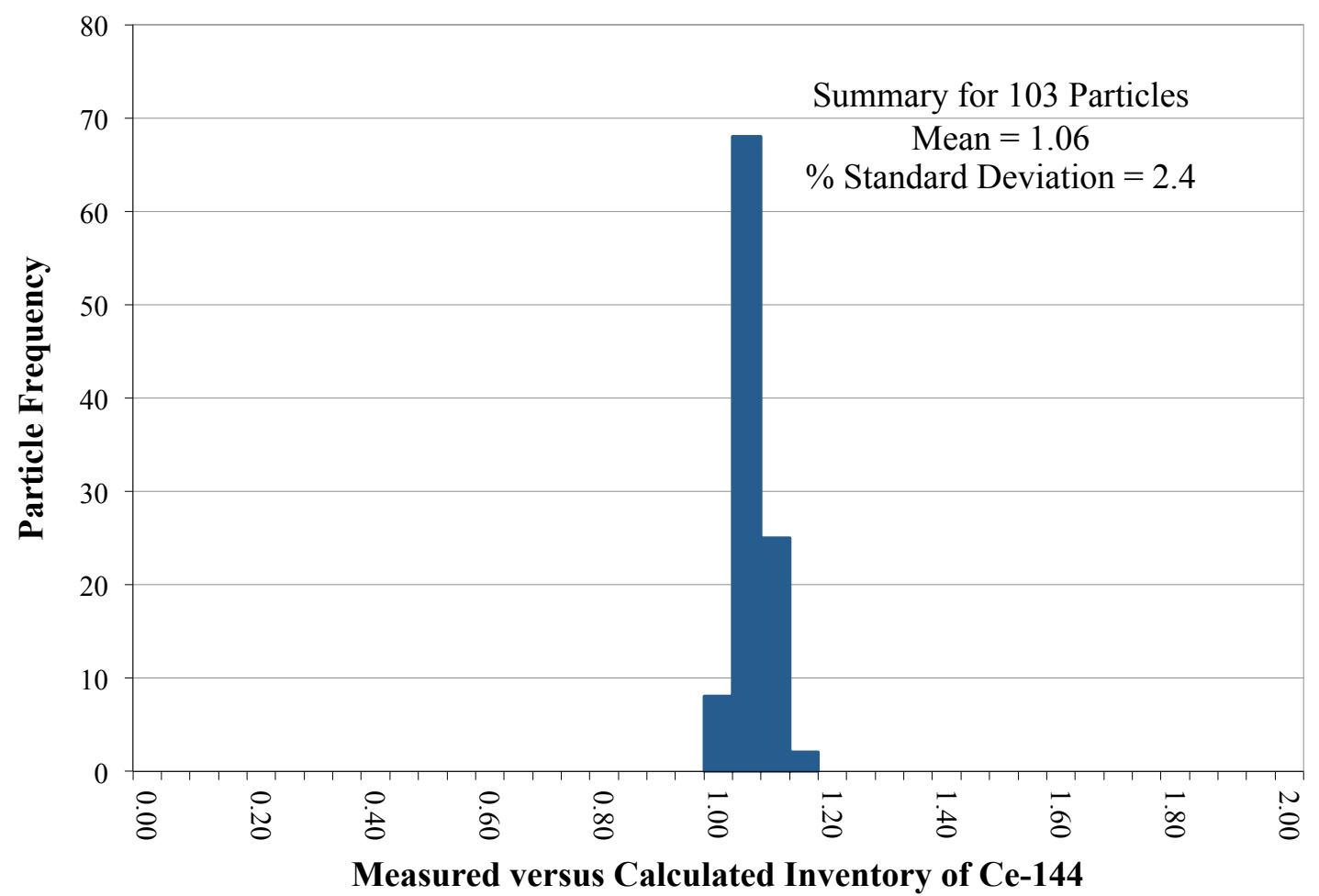

Figure 7. Ratio of ${ }^{144} \mathrm{Ce}$ retained in 103 particles randomly-selected from Compact 4-2-2 versus calculated inventory, adjusted for variation in fissionable material and burnup with the measured ${ }^{137} \mathrm{Cs}$ activity.

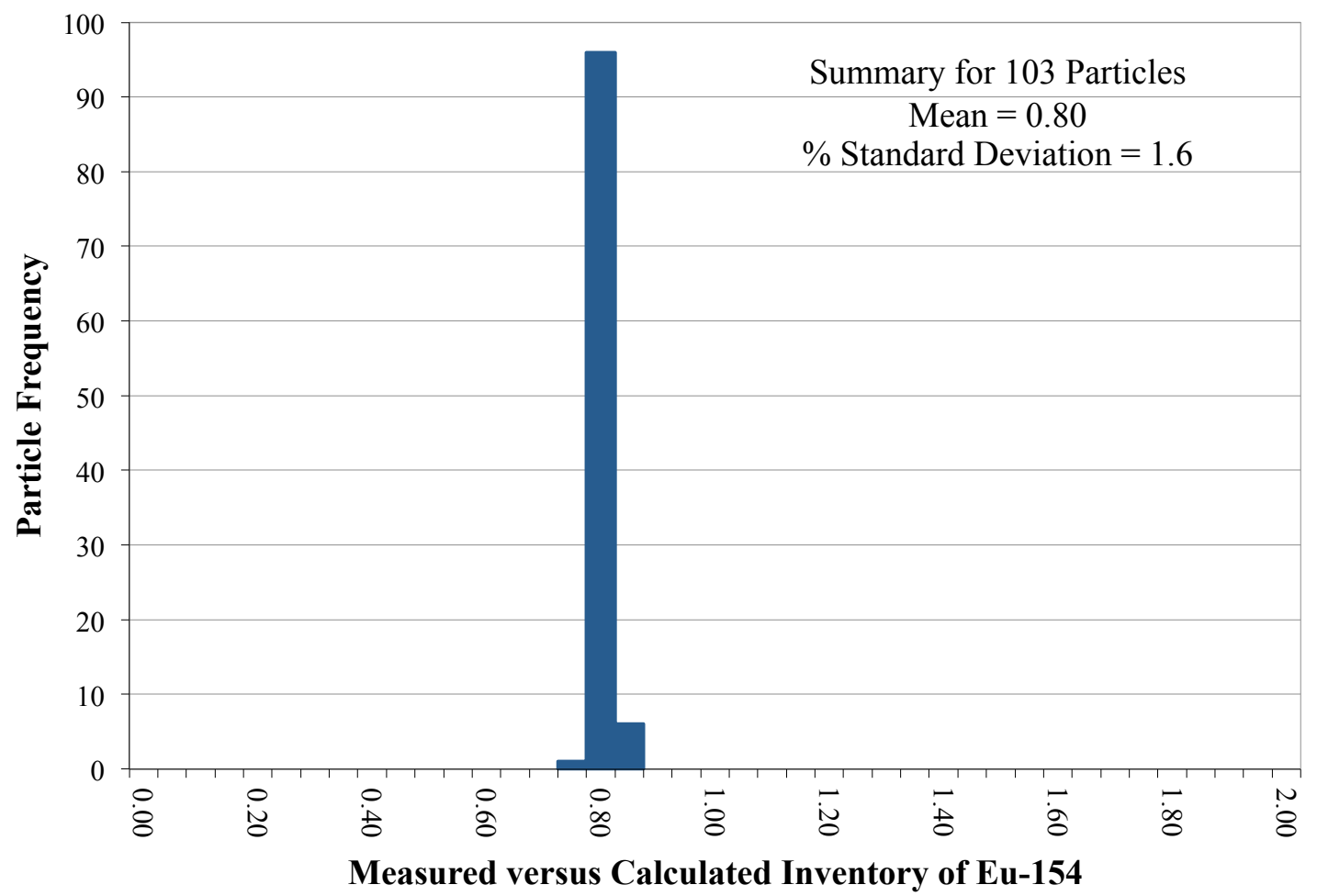

Figure 8. Ratio of ${ }^{154} \mathrm{Eu}$ retained in 103 particles randomly-selected from Compact 4-2-2 versus calculated inventory, adjusted for variation in fissionable material and burnup with the measured ${ }^{137} \mathrm{Cs}$ activity. 
ORNL/TM-2015/033-R0

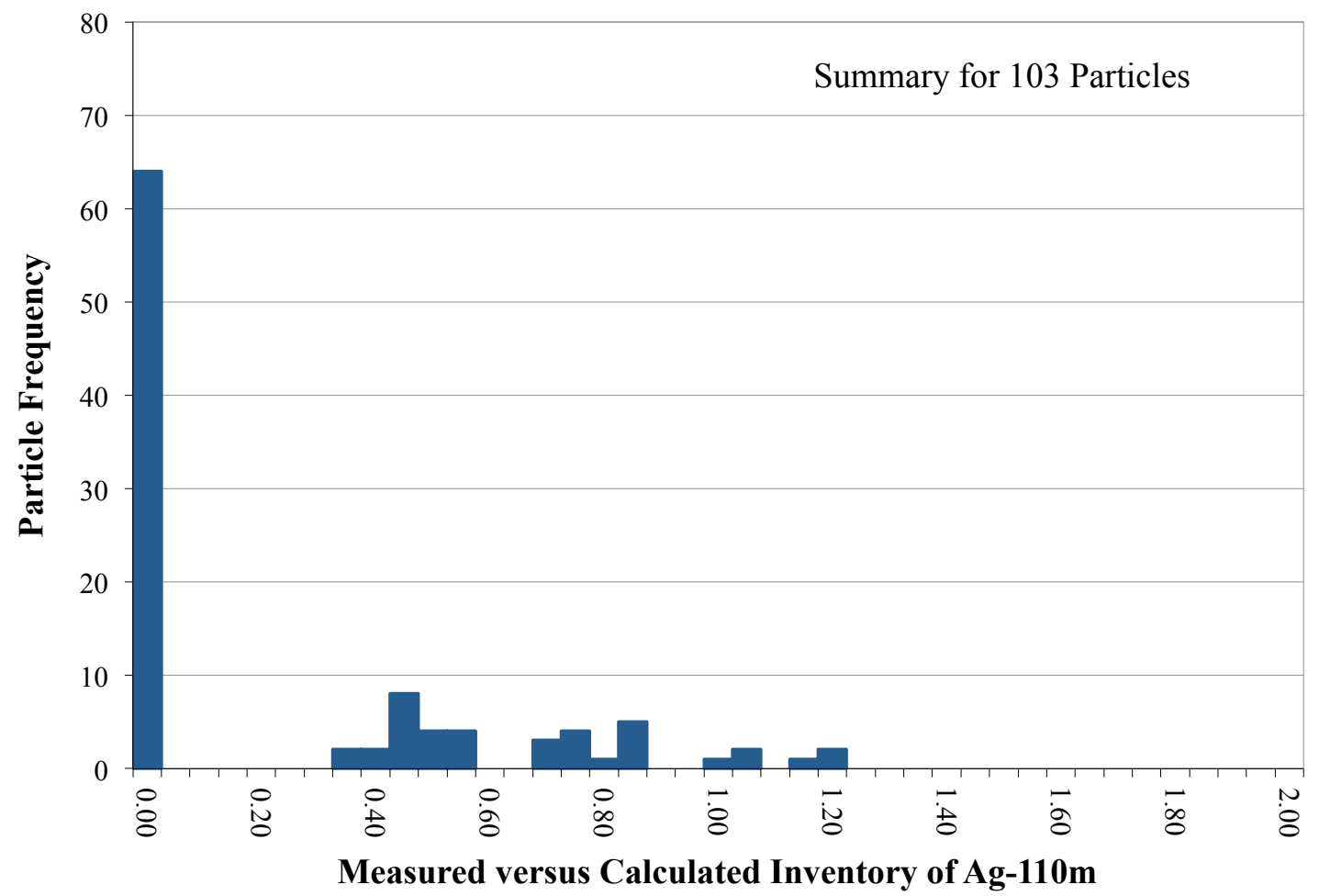

Figure 9. Ratio of ${ }^{110 \mathrm{~m}} \mathrm{Ag}$ retained in 103 particles randomly-selected from Compact 4-2-2 versus calculated inventory, adjusted for variation in fissionable material and burnup with the measured ${ }^{137} \mathrm{Cs}$ activity. Note that the ${ }^{110 \mathrm{~m}} \mathrm{Ag}$ activity in these particles was very low at the time of analysis and uncertainty in peak analysis ranged from $\sim 20 \%$ for particles with more silver to $\sim 53 \%$ for particles with barely detectable silver. The 64 particles with undetectable inventory contained less than a minimum detectable $\mathrm{M} / \mathrm{C}$ of $0.21-0.34$.

Figure 7 and Figure 8 show narrow inventory distributions for ${ }^{144} \mathrm{Ce}$ and ${ }^{154} \mathrm{Eu}$ that are indicative of good fission product retention. In contrast, Figure 9 shows a wide spread in the ${ }^{110 \mathrm{~m}} \mathrm{Ag}$ inventory in each particle, and most particles retained less than the total ${ }^{110 \mathrm{~m}} \mathrm{Ag}$ inventory generated by the AGR-1

irradiation experiment; this clearly indicates silver was released from these particles. A similarly-broad silver distribution has also been observed in particles deconsolidated from as-irradiated compacts, such as Compact 5-2-1 (Figure 10). Compact gamma scanning prior to safety testing [Harp 2013] determined that Compact $4-2-2$ had released $60.3 \%$ of the calculated ${ }^{110 \mathrm{~m}} \mathrm{Ag}$ inventory at the end of the AGR-1 irradiation test, and an additional $6.0 \%$ was released in the CCCTF by the end of the furnace test (Table 1). This equates to a silver retention of $33.7 \%$ in the post-safety test compact. Leaching indicated that there was very little silver left outside of the particles (Table 4), so the average particle inventory should be around $33.7 \%$, which is in agreement with the post-safety test average particle inventory range measured by IMGA of $25-48 \%$ (Table 5). 
ORNL/TM-2015/033-R0

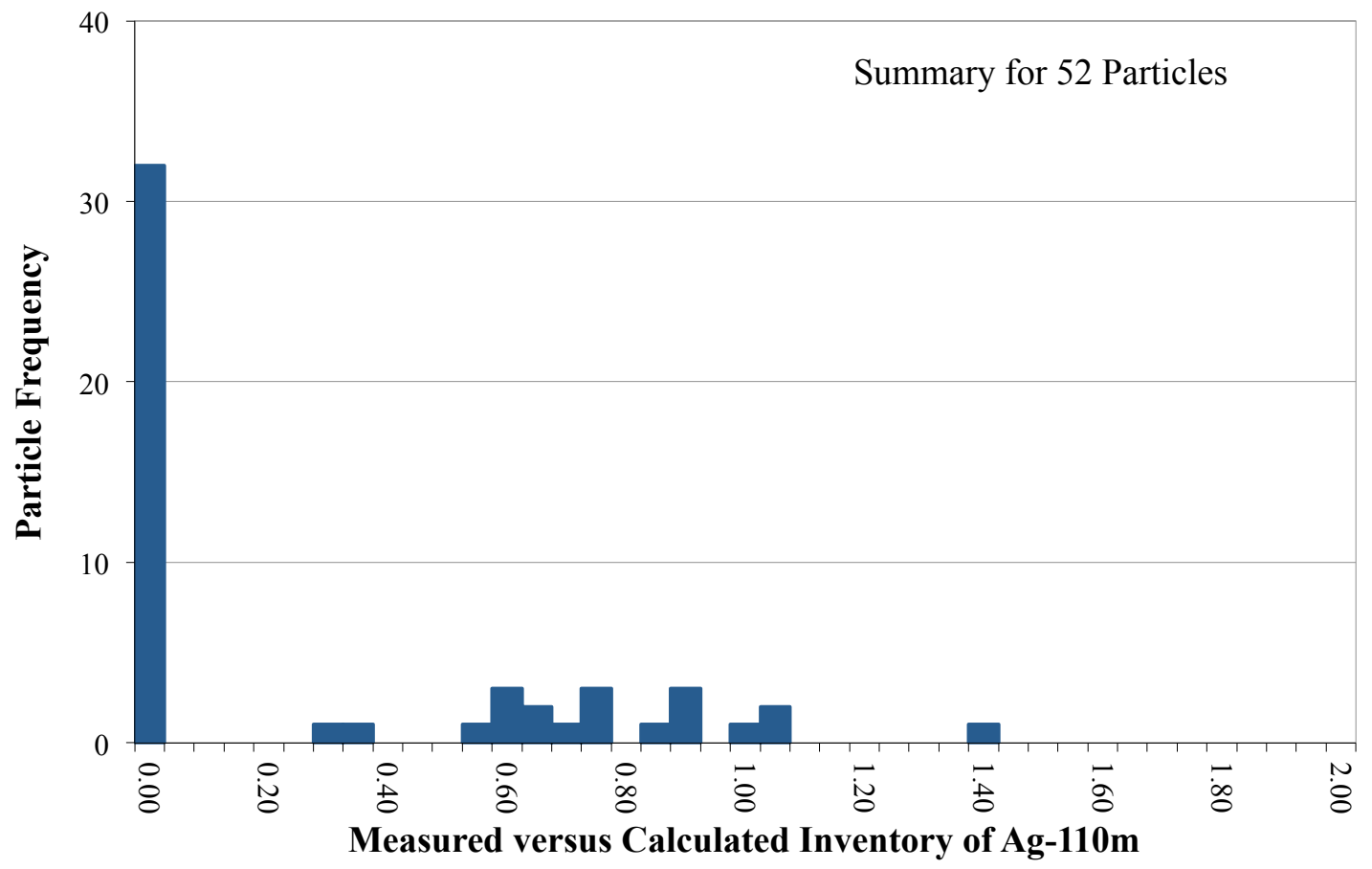

Figure 10. Ratio of ${ }^{110 \mathrm{~m}} \mathrm{Ag}$ retained in 52 particles randomly-selected from Compact 5-2-1 versus calculated inventory, adjusted for variation in fissionable material and burnup with the measured ${ }^{137} \mathrm{Cs}$ activity. Note that the ${ }^{110 \mathrm{~m}} \mathrm{Ag}$ activity in these particles was low at the time of analysis and uncertainty in peak analysis ranged from $\sim 12 \%$ for particles with more silver to $\sim 46 \%$ for particles with barely detectable silver. The 52 particles with undetectable inventory contained less than a minimum detectable $\mathrm{M} / \mathrm{C}$ of $0.22-0.27$.

\section{MICROSTRUCTURAL ANALYSIS OF INDIVIDUAL PARTICLES}

After IMGA on the randomly-selected sample of 103 particles from Compact 4-2-2, particles were selected for x-ray tomography and materialography. Comparison was made between particles from three portions of the ${ }^{110 \mathrm{~m}} \mathrm{Ag}$ distribution shown in Figure 9; those with high silver release (undetectable retention), particles with moderate silver release (M/C of $0.43-0.45)$, and particles with low silver release $(\mathrm{M} / \mathrm{C}$ of 1.03-1.21). Figure 11 shows $\mathrm{x}$-ray tomographs near midplane of three such particles; these particles had significantly different silver retention, but very similar microstructures typical for AGR-1 irradiated TRISO [Ploger, Demkowicz, and Hunn 2012]. All three particles exhibited a large gap between the buffer and IPyC, where the shrinking buffer tore away from the IPyC. There was little significant change to the three outer layers, other than some fission product pileup (bright spots) at the IPyC/SiC interface and a small gap between the $\mathrm{SiC}$ and the $\mathrm{OPyC}$, both of which are more evident in the optical and SEM-imaged cross sections discussed below. Fission product pileup at the IPyC/SiC interface occurs during irradiation, but has only been observed in rare cases to lead to $\mathrm{SiC}$ failure when the fission product concentration (predominantly palladium) is abnormally high due to IPyC fracture and exposure of the inner surface of the SiC layer [Hunn et al. 2014-4]. It cannot be ruled out that some of the observed pileup may have occurred in the Compact 4-2-2 particles during heating in the CCCTF, but the number and size of the clusters at the IPyC/SiC interface was not different from what has been observed in as-irradiated fuel. The small gap between the $\mathrm{SiC}$ and the OPyC has also been observed in as-irradiated fuel particles [Hunn et al. 2013-1, page 35], and has been noted to broaden as a function of increasing safety test temperature [Hunn et al. 2013-2, page 27]. This gap may be formed as a result of shrinkage in the compact matrix pulling the $\mathrm{OPyC}$ away from the $\mathrm{SiC}$; the interface strength between the non-porous outer surface of the $\mathrm{SiC}$ and the OPyC layer can be assumed to be weaker than that between the porous outer surface of the OPyC and the compact matrix. 

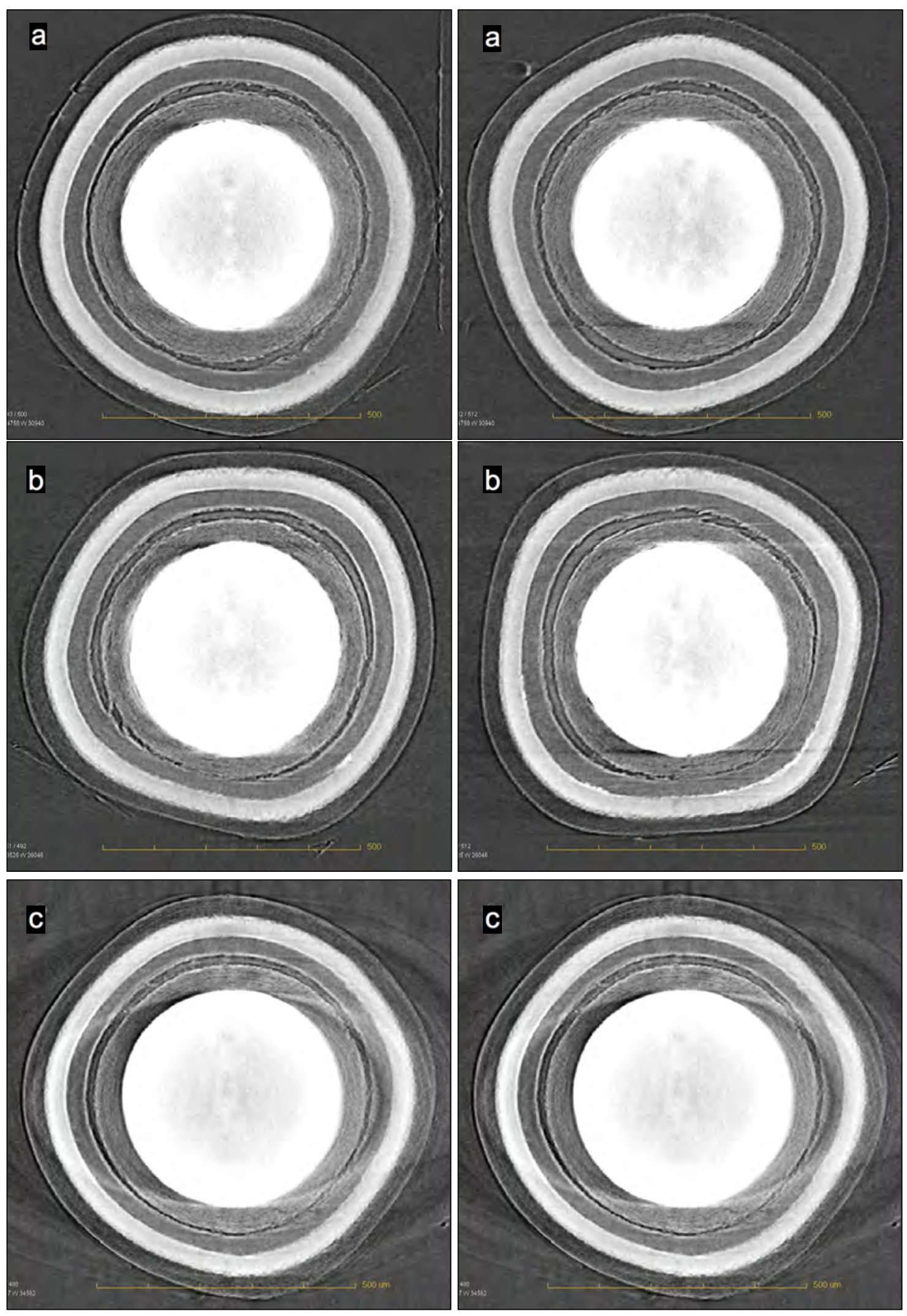

Figure 11. Orthogonal pairs of X-ray tomographs near midplane for three particles from Compact 4-2-2: (a) Particle 422-RS71 with high ${ }^{110 \mathrm{~m}} \mathrm{Ag}$ release (M/C $<0.37$ ), (b) Particle 422-RS11 with moderate ${ }^{110 \mathrm{~m}} \mathrm{Ag}$ release $(\mathrm{M} / \mathrm{C}=0.45)$, and (c) Particle $422-\mathrm{RS} 21$ with very low ${ }^{110 \mathrm{~m}} \mathrm{Ag}$ release $(\mathrm{M} / \mathrm{C}=1.06)$. Streaks extending from top and bottom of kernels are reconstruction artifacts. 
Figure 12 shows optical micrographs of three additional particles from the randomly-selected IMGA sample, after grinding and polishing to midplane. These particles also show the typical buffer densification and buffer/IPyC delamination, similar to the internal microstructures in the particles examined by x-ray. Kernel structure in the three particles varied in the distribution and appearance of the porosity; this variability in the irradiated kernel structure is mostly related to a variability in the preirradiated uranium carbide/uranium oxide (UCO) fuel kernel structure [Hunn et al. 2012, pages 45-49] and has not been found to correlate to silver-retention behavior. A 3- $\mu \mathrm{m}$-wide gap (filled with backpotting epoxy) can be seen between the $\mathrm{SiC}$ and OPyC layers of the higher magnification image in Figure 12b.
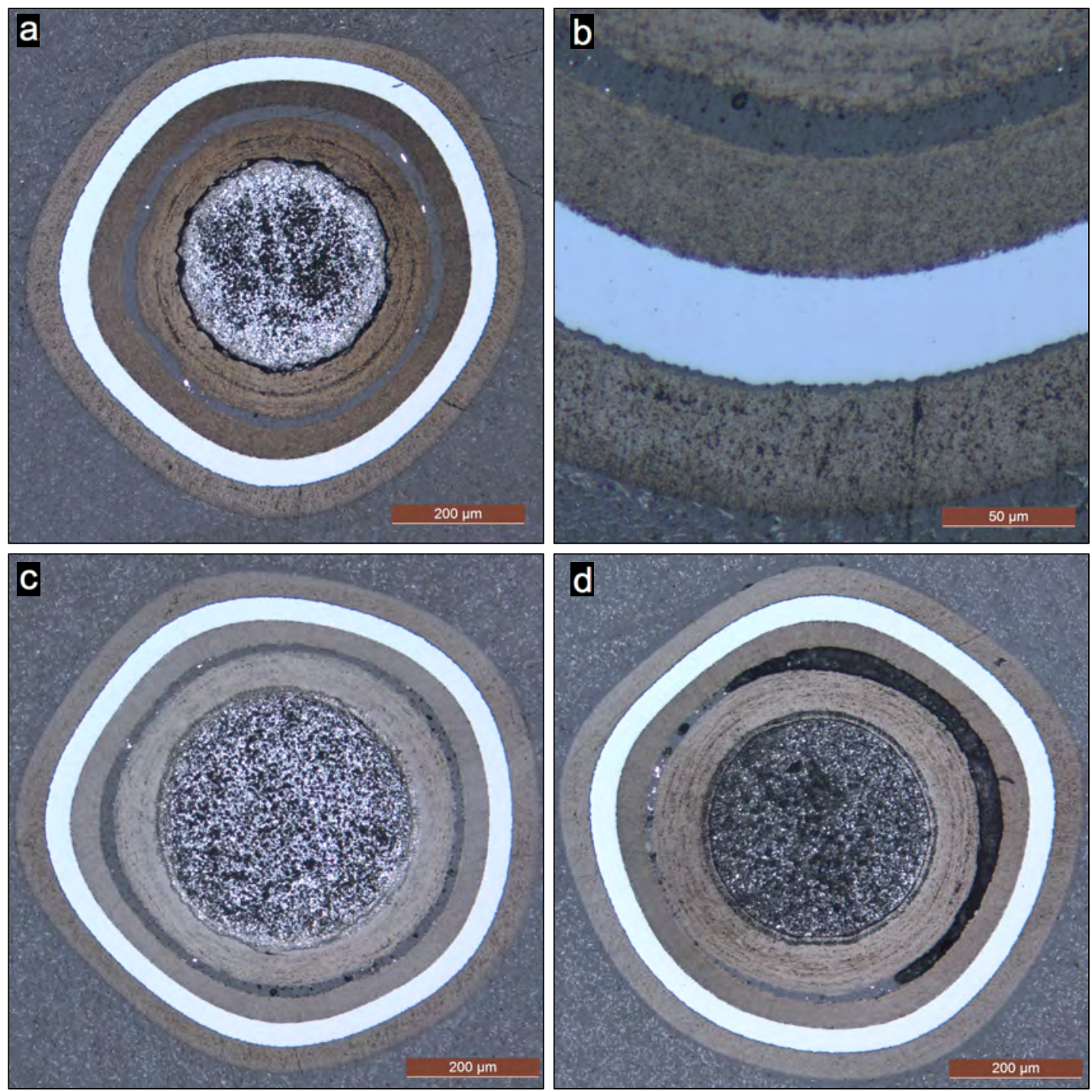

Figure 12. Optical micrographs near midplane of particles from Compact 4-2-2: (a\&b) Particle 422-RS57 with high ${ }^{110 \mathrm{~m}} \mathrm{Ag}$ release $(\mathrm{M} / \mathrm{C}<0.38)$, (c) Particle $422-\mathrm{RS} 45$ with moderate ${ }^{110 \mathrm{~m}} \mathrm{Ag}$ release $(\mathrm{M} / \mathrm{C}=0.43)$, and (d) Particle 422-RS23 with very low ${ }^{110 \mathrm{~m}} \mathrm{Ag}$ release $(\mathrm{M} / \mathrm{C}=1.21)$. If kernel and buffer were detached from outer three coating layers, they may have shifted before backpotting and not be near midplane.

SEM imaging was performed on the sectioned Compact 4-2-2 particles shown in Figure 12 after optical imaging and additional polishing with $0.04-\mu \mathrm{m}$-grain colloidal silica. Figure 13-Figure 18 show secondary electron and backscattered electron images at two magnifications of a portion of the outer three layers in each particle. The shallow escape depth of the secondary electrons provides resolution of near surface features, while the backscattered electrons provide slightly-higher probe depth and additional compositional contrast due to increased scatter from atoms with higher atomic number $(Z)$. 


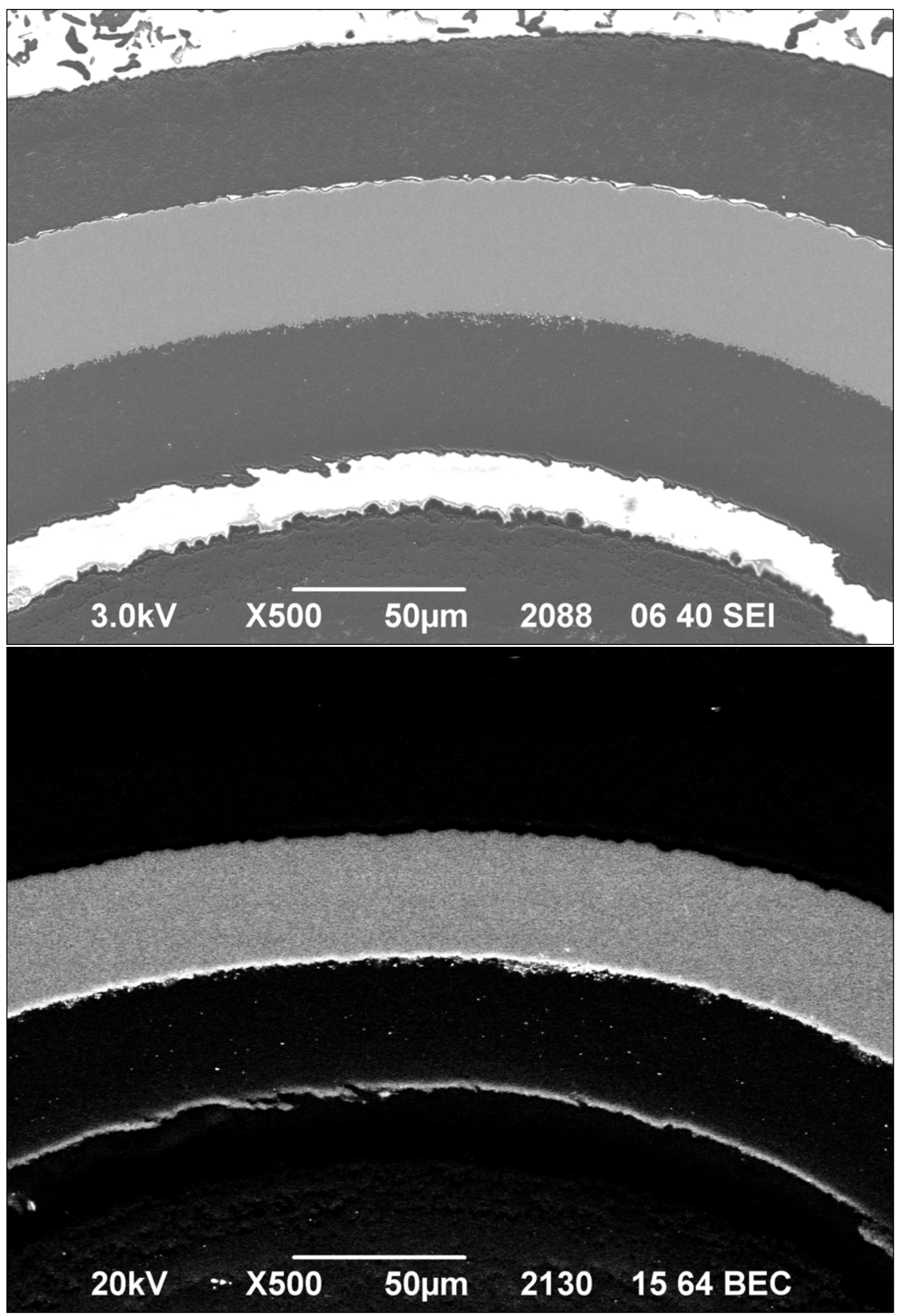

Figure 13. SEI/BEC-paired images of Particle 422-RS57 with high ${ }^{110 \mathrm{~m}} \mathrm{Ag}$ release $(\mathrm{M} / \mathrm{C}<0.38)$ shown in Figure 12a. 

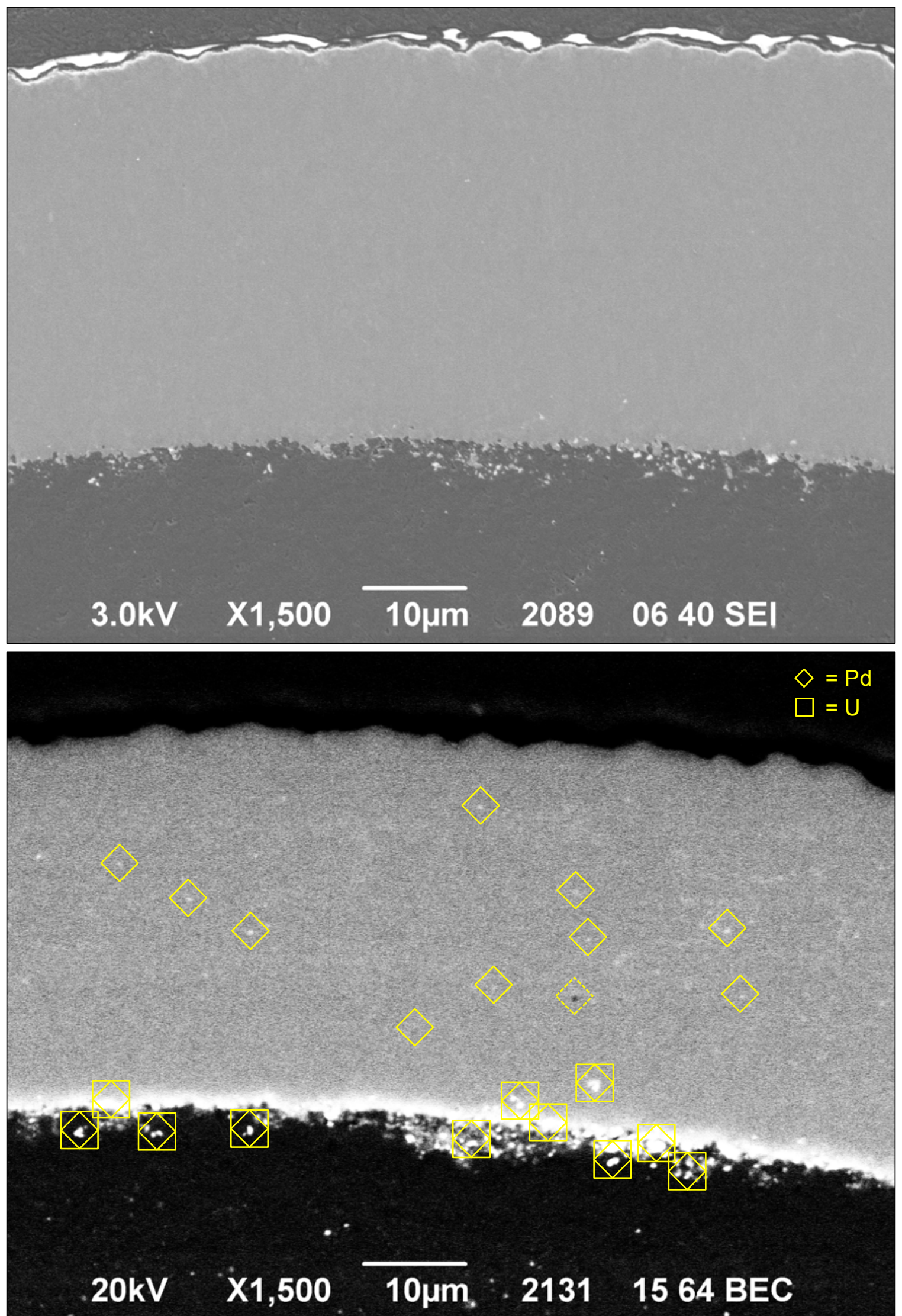

Figure 14. SEI/BEC-paired images of Particle 422-RS57 with high ${ }^{110 \mathrm{~m}} \mathrm{Ag}$ release $(\mathrm{M} / \mathrm{C}<0.38)$ shown in Figure 13. Dashed diamonds or squares indicate relatively-lower signal from Pd or U. 

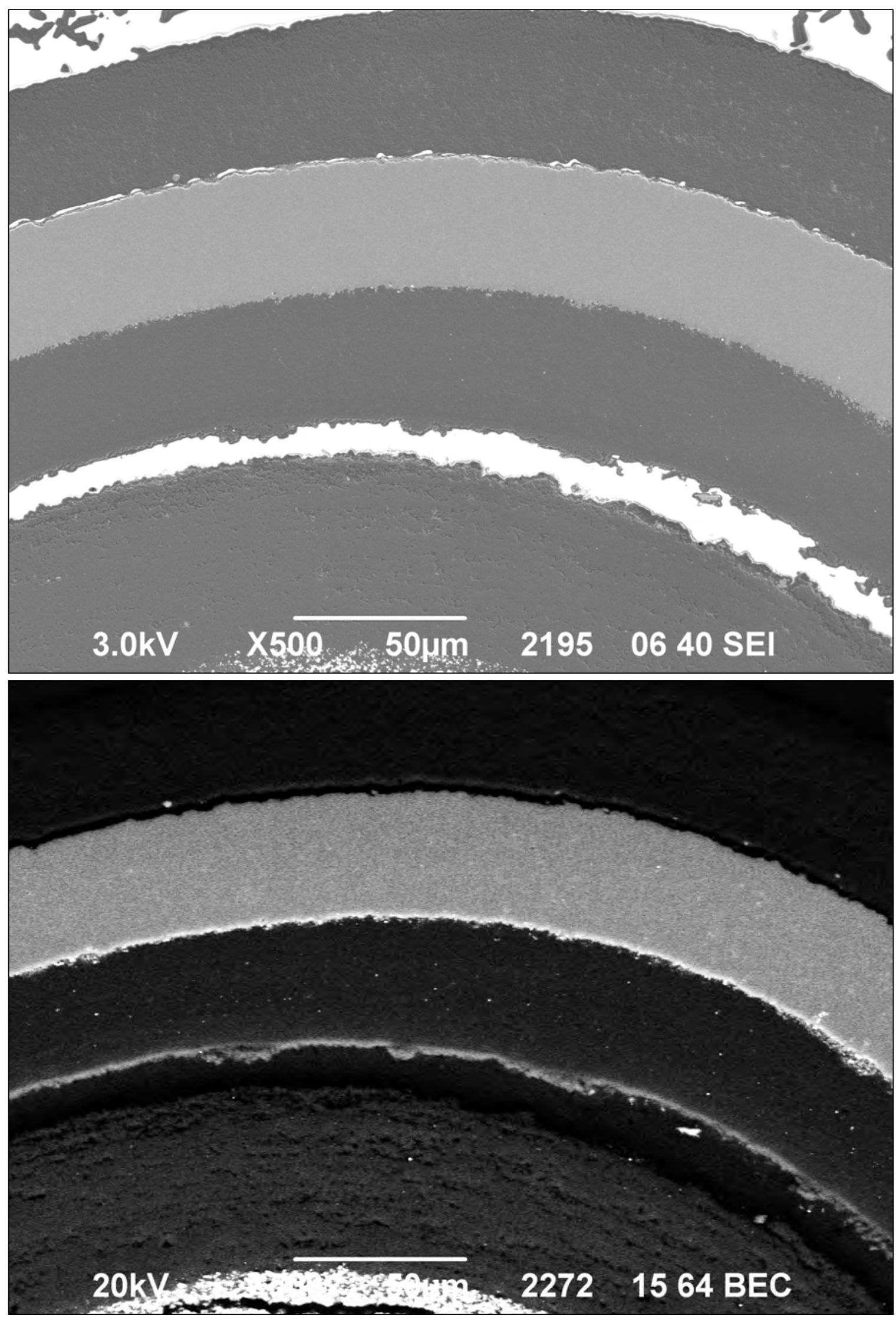

Figure 15. SEI/BEC-paired images of Particle 422-RS45 with moderate ${ }^{110 \mathrm{~m}} \mathrm{Ag}$ release $(\mathrm{M} / \mathrm{C}=0.43)$ shown in Figure 12c. 

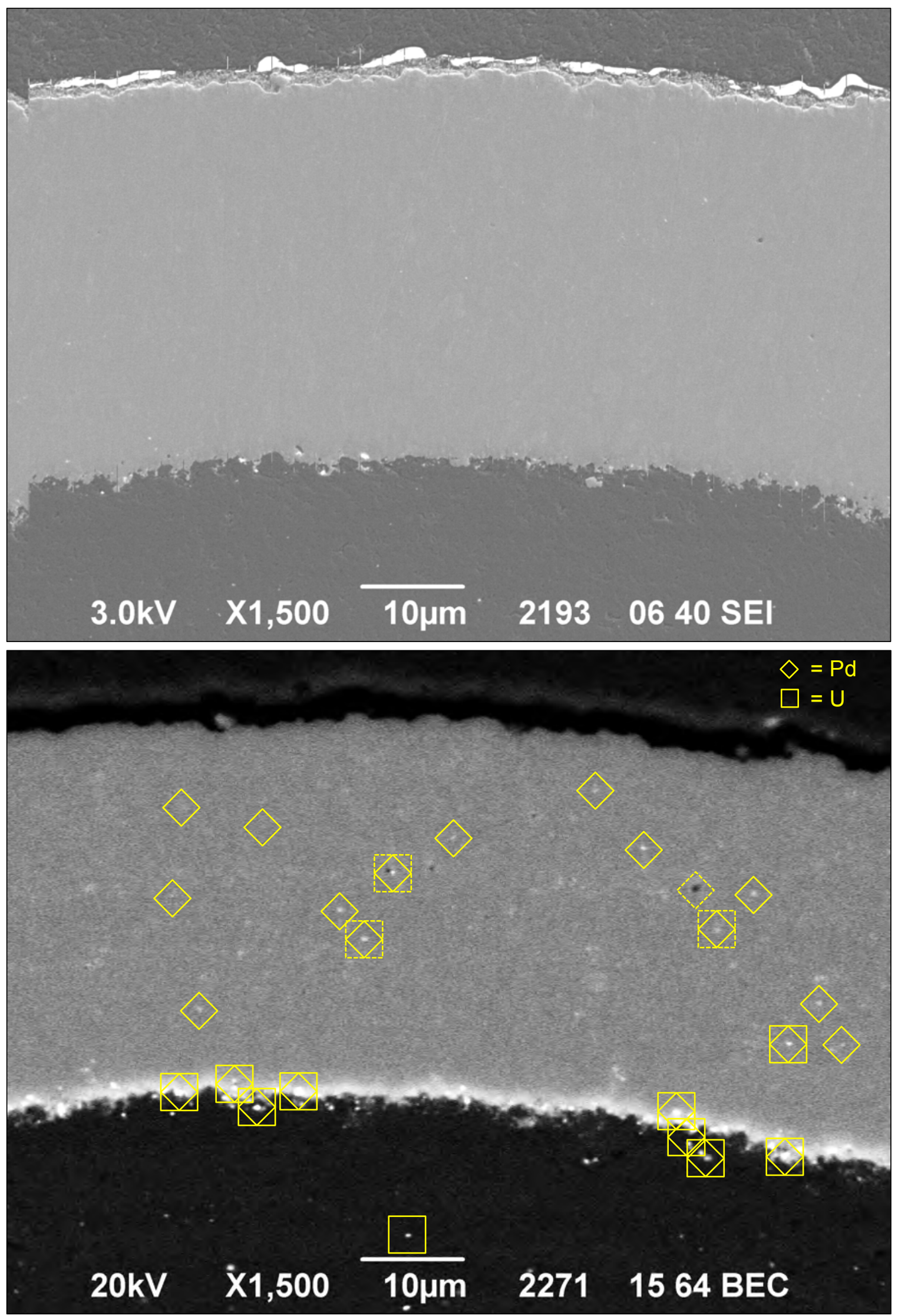

Figure 16. SEI/BEC-paired images of Particle 422-RS45 with moderate ${ }^{110 \mathrm{~m}} \mathrm{Ag}$ release $(\mathrm{M} / \mathrm{C}=0.43)$ shown in Figure 15. Dashed diamonds or squares indicate relatively-lower signal from Pd or U. 

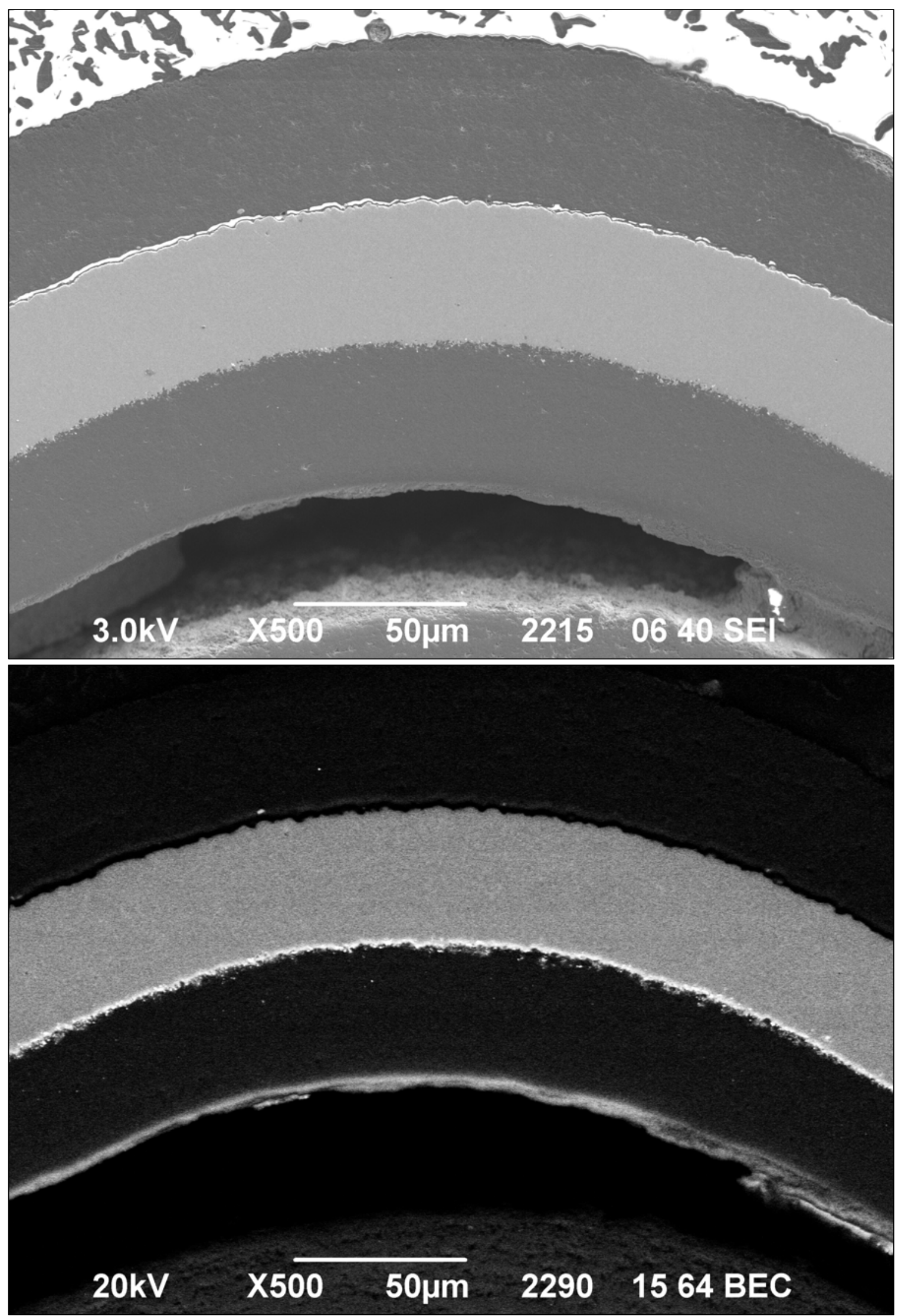

Figure 17. SEI/BEC-paired images of Particle 422-RS23 with very low ${ }^{110 \mathrm{~m}} \mathrm{Ag}$ release $(\mathrm{M} / \mathrm{C}=1.21)$ shown in Figure 12d. 


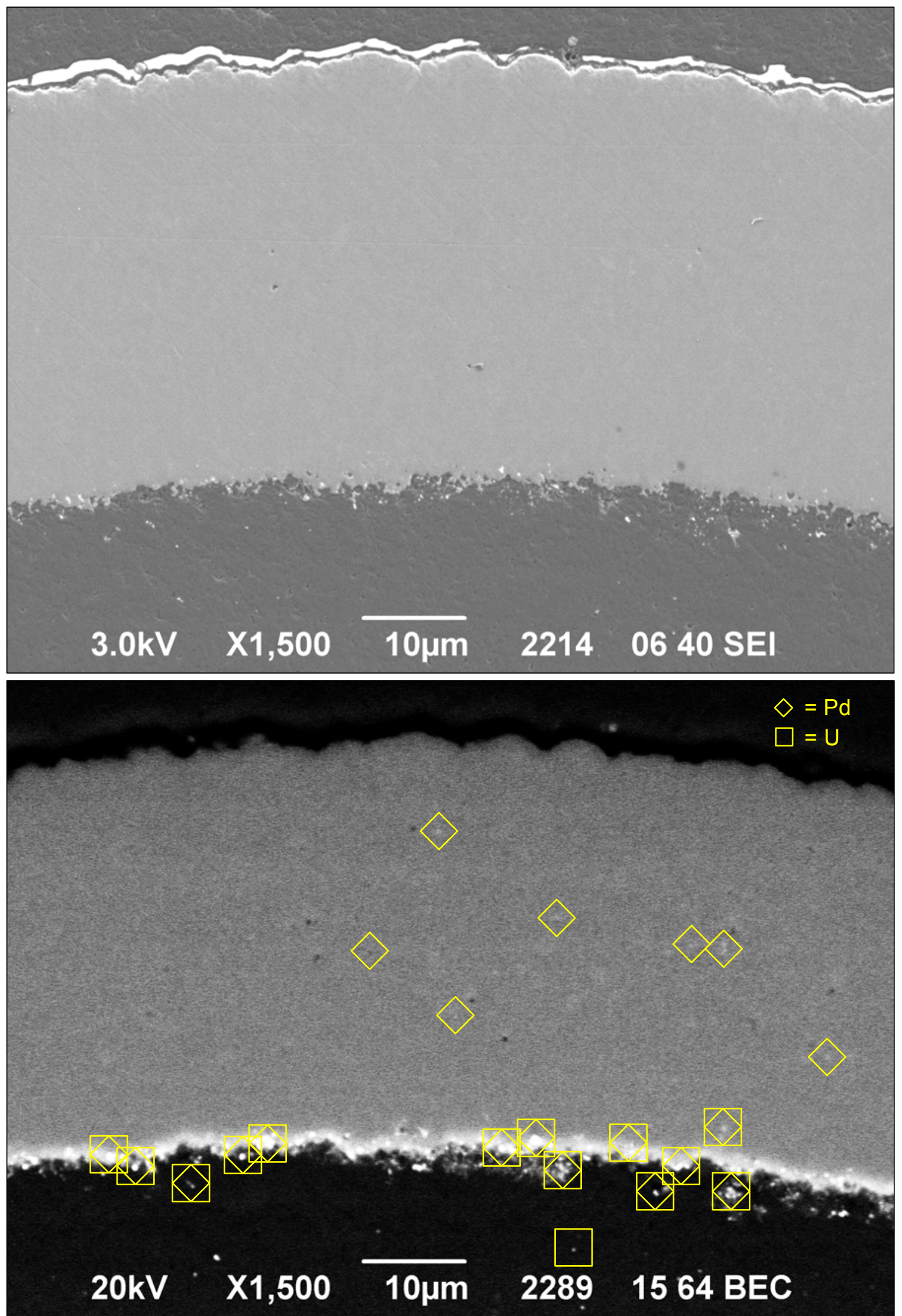

Figure 18. SEI/BEC-paired images of Particle 422-RS23 with very low ${ }^{110 \mathrm{~m}} \mathrm{Ag}$ release $(\mathrm{M} / \mathrm{C}=1.21)$ shown in Figure 17. 
The SEI images in Figure 13-Figure 18 show that the IPyC/SiC interface was well-preserved throughout the irradiation and subsequent safety testing. Bright spots decorating the IPyC/SiC interface are clusters of high-Z fission products. These fission product clusters can also be seen as isolated spots sparselyscattered throughout the IPyC and SiC layers. In the BEC images, the bright spots are more numerous and evident due to the increased compositional contrast and increased probing depth. Bright spots in the BEC images in Figure 14, Figure 16, and Figure 18 were analyzed with EDS, as described in previous reports [Hunn et al. 2012, pages 58-66; Hunn et al. 2014-4, pages 101-107], where similar features were observed in as-irradiated particles. Many of the analyzed features in the Compact 4-2-2 particles are labeled in Figure 14, Figure 16, and Figure 18 to indicate the detected presence of palladium and uranium, which were the predominant fission products found in the $\mathrm{SiC}$. Fission product clusters at the $\mathrm{IPyC} / \mathrm{SiC}$ interface almost always yielded strong EDS peaks from both palladium and uranium, while features further out in the $\mathrm{SiC}$ more often just produced measurable $\mathrm{x}$-ray emission from palladium. Conversely, fission product clusters that were isolated in the IPyC tended to produce strong uranium peaks and none from palladium. Smaller peaks from cesium and barium were observed in the fission product clusters isolated in the IPyC; and fission product clusters at the IPyC/SiC interface sometimes included these two elements and others $(\mathrm{Pu}, \mathrm{Nd}, \mathrm{Ce}, \mathrm{Rh}, \mathrm{Zr})$.

Although this was not studied in depth for Compact 4-2-2, Figure 14, Figure 16, and Figure 18 show palladium distributions that appear to be consistent with the general trend for fission product distribution in the $\mathrm{SiC}$ as a function of silver retention discussed in previous reports [Hunn et al. 2013-1, page 58; Hunn et al. 2014-2, page 18; Hunn et al. 2014-3, pages 16-18; Hunn et al. 2014-4, page 82]. In particles that release larger fractions of their silver inventories, palladium clusters tend to be more numerous overall and at a higher frequency further out into the $\mathrm{SiC}$, whereas particles that retain silver well also tend to show less penetration of palladium into the $\mathrm{SiC}$ layer. Image analysis is being performed to quantify the clustered fission product penetration depth versus silver retention in as-irradiated and safetytested fuel particles, and this detailed analysis will be reported in a future paper.

The EDS analysis performed on dark spots in the $\mathrm{SiC}$ showed that these regions are almost always carbon-rich and often contain traces of palladium (Figure 14 and Figure 16). Similar dark spots have been observed in other safety-tested particles and appear to be indicative of regions where palladium silicide has formed and subsequently migrated away. In safety tests performed at $1800^{\circ} \mathrm{C}$ [Hunn et al. $2013-2$, page 28; Hunn et al. 2014-2, page 24], migration of palladium out of the $\mathrm{SiC}$ was more pronounced and the frequency of dark spots was greater than observed in particles safety tested at lower temperatures.

Of the nine particles selected for microstructural analysis, only one exhibited buffer fracture accompanied by kernel protrusion. This type of radiation-induced damage is not unusual for AGR-1 fuel (229 out of 981 particles observed during compact ceramography showed this effect [Ploger et al. 2012]); however, Particle 422-RS60 experienced an unusually-extreme amount of kernel protrusion into the gap created by the buffer fracture. Figure 19 shows a polished section close to midplane where the kernel fills nearly all the space between its original boundary and the inner surface of the IPyC. A portion of the buffer appears to be missing; presumably, the buffer fragment that would match up with the fractured edges of the buffer visible in this image has been displaced such that it is not visible in the imaged plane. Unfortunately, this particle was not subjected to three-dimensional x-ray tomography, which would have elucidated the actual internal structure of the particle. The shape of the IPyC layer does not indicate any unusual buffer shape or missing volume at the time of deposition. Analysis of the kernel in the SEM using EDS did not show anything unique in the kernel structure or elemental composition other than the large internal pores that are typical for a kernel that has experienced less-constrained swelling. The outer layers of the particle appear to be intact. The SEM montages in Figure 20 and Figure 21 show that there is a little more fission product pileup at the $\mathrm{IPyC} / \mathrm{SiC}$ interface in the region adjacent to the kernel protrusion, but there is no noticeable degradation of the $\mathrm{SiC}$. 


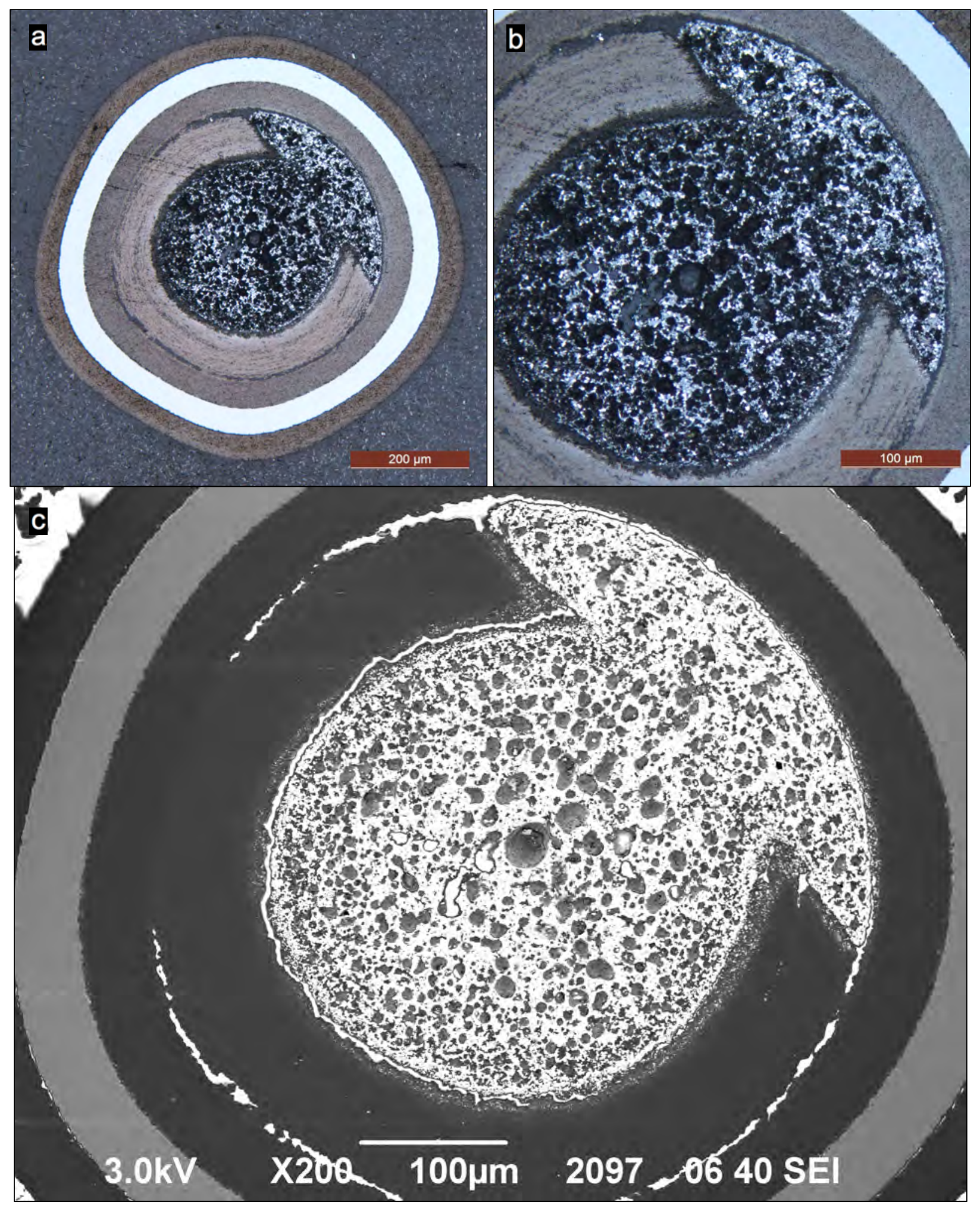

Figure 19. Polished section near midplane of Particle 422-RS60 with high ${ }^{110 \mathrm{~m}} \mathrm{Ag}$ release $(\mathrm{M} / \mathrm{C}<0.38)$ : (a\&b) optical micrographs and (c) SEI image. 
ORNL/TM-2015/033-R0

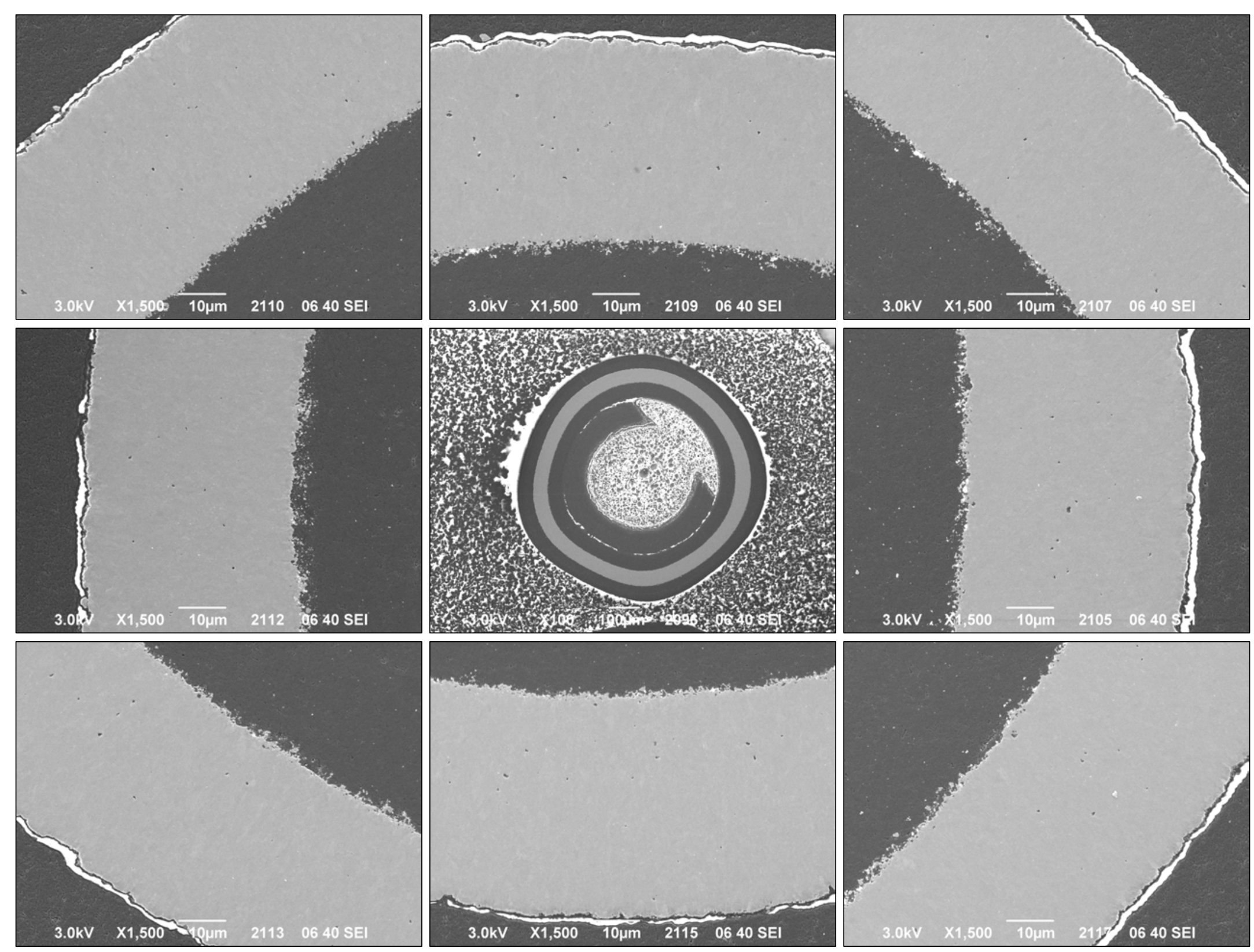

Figure 20. SEI montage of Compact 4-2-2 Particle 422-RS60 shown in Figure 19. 


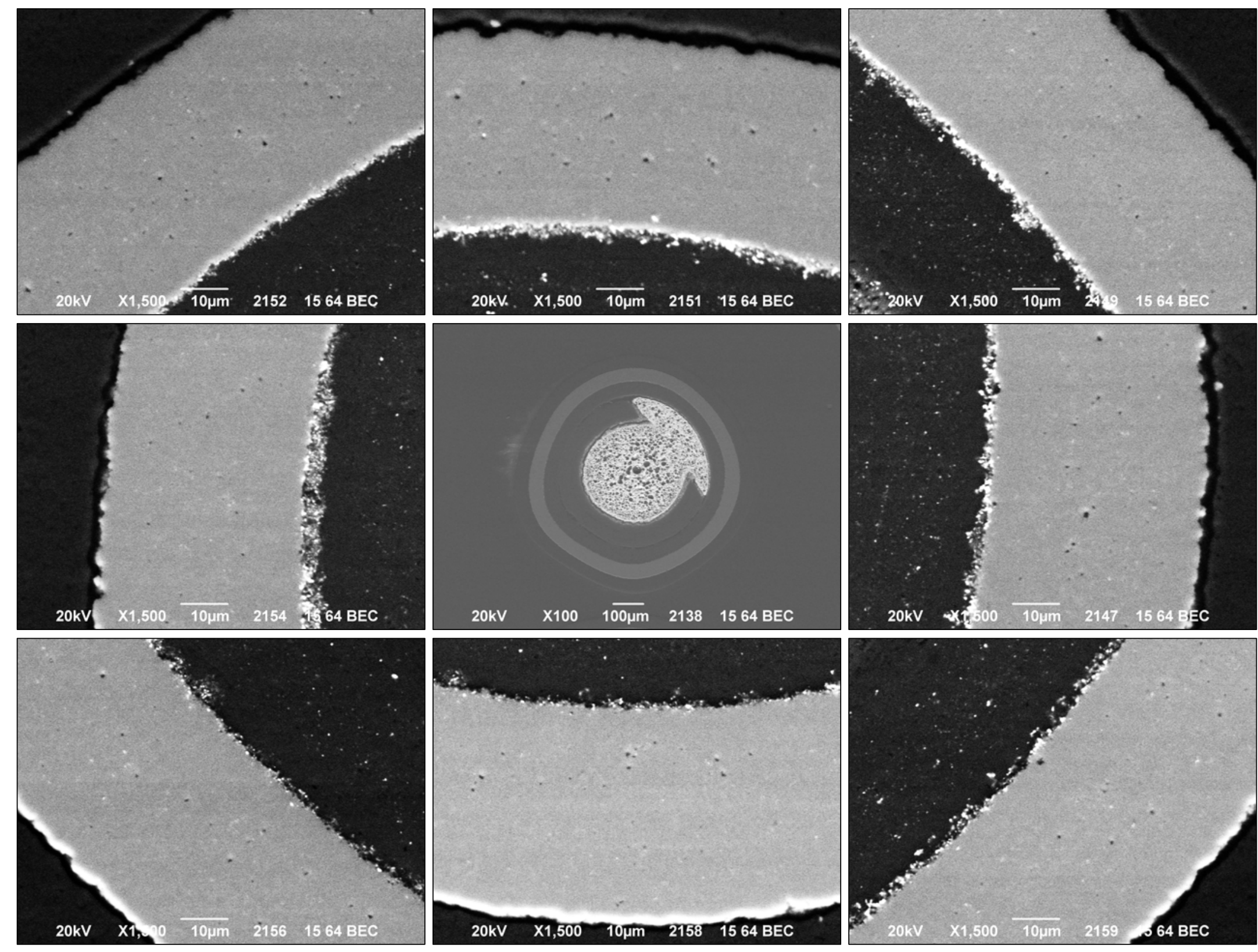

Figure 21. BEC montage of Compact 4-2-2 Particle 422-RS60 shown in Figure 19. 


\section{SUMMARY AND CONCLUSIONS}

A multiple-temperature furnace test was conducted to investigate previous unexpected silver releases that occurred in a few early AGR-1 safety tests due to power failures and other CCCTF issues. Compact 4-2-2 was first heated to $1600^{\circ} \mathrm{C}$ to flush out silver that was expected to be in the compact matrix and OPyC due to release through intact $\mathrm{SiC}$ during irradiation testing. After the silver release rate at $1600^{\circ} \mathrm{C}$ dropped to a negligible value, the compact was subjected to 72 hour holds at progressively lower temperatures. While no additional silver was released at $1450^{\circ} \mathrm{C}$, subsequent holds at 1300 and $1150^{\circ} \mathrm{C}$ resulted in additional silver release, similar to what had been observed in the previous safety tests when temperature was unexpectedly cycled. A rapid thermal cycle from $1600^{\circ} \mathrm{C}$, down to room temperature, and back to $1600^{\circ} \mathrm{C}$ did not release additional silver; this indicates that the observed additional silver releases were dependent on the fuel temperature rather than the changing temperature. Observations from this study suggest that there is a release mechanism for silver through intact $\mathrm{SiC}$ that is only active in a limited temperature range that is below the standard $1600-1800^{\circ} \mathrm{C}$ safety test temperatures and at the high end of gas reactor operating temperatures.

Release of other fission products during the heating test was similar to what has been observed in other single-temperature safety tests. There was no significant ${ }^{85} \mathrm{Kr}$ release, indicating that at least one of the three gas-tight outer layers of the TRISO coating in every particle (IPyC, SiC, or OPyC) remained intact throughout the duration of each test. There was also no significant cesium release, indicating that all particles had intact SiC layers. Europium and strontium were slowly released throughout the test, with higher release rates observed at the higher temperatures. This behavior is consistent with the hypothesis that europium and strontium, previously released through intact $\mathrm{SiC}$ during irradiation, slowly move through the carbonaceous material of the compact matrix and CCCTF graphite holder; however, it cannot be ruled out that some small fraction of europium and strontium may be passing through intact $\mathrm{SiC}$ during the safety test.

Post-safety testing PIE consisted of DLBL, IMGA, x-ray tomography, and materialographic inspection by mechanical cross sectioning followed by optical and electron microscopy. Data was obtained on radioisotope retention and microstructural changes that occurred during irradiation and the subsequent multiple-temperature furnace testing. DLBL showed that silver and palladium, which are usually found in abundance outside the $\mathrm{SiC}$ in as-irradiated compacts, were negligibly retained in the Compact 4-2-2 matrix and $\mathrm{OPyC}$ after the furnace test. This is a typical result after safety testing and is consistent with the assumption that, once silver was released through intact $\mathrm{SiC}$, it moved rapidly out of the heated compact. In contrast, the exposed inventories of europium and strontium were higher in the compact than what was collected during safety testing. It is not unusual for safety tested compacts to retain more of these slower migrating elements than they release. Low concentrations of uranium and plutonium in the DLBL solutions (summing to only a few tenths of one kernel's inventory) supported the conclusion that no $\mathrm{SiC}$ coatings failed during the irradiation or furnace test. Because no failed $\mathrm{SiC}$ was indicated by the furnace test and deconsolidation-leach results, short-scan survey of all the particles with IMGA was not performed.

Long-scan gamma counting of 103 particles determined that most of the particles in Compact 4-2-2 had released the majority of their silver inventory (64 particles had an undetectable ${ }^{110 \mathrm{~m}} \mathrm{Ag}$ inventory of $<34 \%$ ). However, most of this silver release occurred during the irradiation test and without pre-safety test inventory data for each particle, no conclusions can be drawn regarding individual particle release during the Compact 4-2-2 furnace test. Measured inventory of other gamma-emitting radioisotopes in the randomly-selected particle sample were within expected ranges.

Microstructures observed in randomly-selected particles extracted from the safety tested compacts were similar to those seen in as-irradiated fuel [Ploger, Demkowicz, and Hunn 2012; Hunn, Savage, and Kehn 2012; Hunn et al. 2013-1; Hunn et al. 2014-4]. Shrinkage of the buffer layer and swelling of the kernel were common to all particles. Buffer shrinkage led to buffer/IPyC delamination but only one particle out of the nine selected for analysis exhibited buffer fracture; this buffer fracture was accompanied by an 
unusual degree of kernel protrusion into the gap between the buffer fragments, with the kernel filling almost all the available space when viewed as a polished cross section.

SEM imaging showed excellent retention of the as-fabricated IPyC/SiC interface, which remained intimately bonded by SiC infiltration into the outer porosity of the IPyC layer. Fission products (particularly palladium and uranium) could be seen sparsely clustered throughout the IPyC and $\mathrm{SiC}$ layers and concentrated in larger and denser patterns in the inter-stitched region at the IPyC/SiC interface. EDS analysis showed that palladium and uranium were collocated in clusters at or near the IPyC/SiC interface, while isolated clusters in the $\mathrm{SiC}$ were predominantly palladium and those in the IPyC contained mostly uranium. Although statistical sampling from this one compact was not sufficient to draw any independent conclusions, particles that exhibited higher silver release tended to have clusters of palladium scattered further out into the $\mathrm{SiC}$ layer, while particles with low silver release tended to have fewer clusters further than $10 \mu \mathrm{m}$ away from the IPyC/SiC interface; this is consistent with previous observations that help support an overall hypothesis that palladium and silver migration through $\mathrm{SiC}$ may be related or at least occur under similar conditions [Hunn et al. 2013-1, page 58; Hunn et al. 2014-2, page 18; Hunn et al. 2014-3, pages 16-18; Hunn et al. 2014-4, page 82]. Dark spots in the SEM images of the SiC were carbon-rich zones containing only traces of palladium, if any at all was detected. These dark spots have also been observed in other safety tested compacts and are consistent with a conclusion that palladium is mobile in $\mathrm{SiC}$ at safety-test temperatures, particularly at $1800^{\circ} \mathrm{C}$ [Hunn et al. 2013-2, page 28; Hunn et al. 2014-2, page 24] where the $\mathrm{SiC}$ away from the IPyC/SiC interface often appears denuded of palladium leaving behind carbon-rich regions or uranium-only clusters; in as-irradiated compacts, these features would typically include significant concentrations of palladium.

Additional experiments need to be performed to further verify and explore the silver release behavior observed when Compact 4-2-2 was held at temperatures between 1075 and $1375^{\circ} \mathrm{C}$. One concern is the low magnitude of the observed silver release. Only $6 \%$ of the calculated silver inventory was released in the CCCTF, and about three-quarters of this was released during the first $1600^{\circ} \mathrm{C}$ bake (Table 1 and Figure 2). The low inventory fraction involved in the additional silver releases between 1075 and $1375^{\circ} \mathrm{C}$, coupled with the fact that Compact 4-2-2 had gone almost seven ${ }^{110 \mathrm{~m}} \mathrm{Ag}$ half lives by the time of the study, increases the uncertainty in the results and makes the measurements vulnerable to experimental artifacts. Previous additional silver releases observed during safety testing of Compact 3-3-2 (Figure 4) were close to $10 \%$ of the ${ }^{110 \mathrm{~m}} \mathrm{Ag}$ inventory generated by the irradiation test, so this effect is expected to involve larger quantities of silver, if available in particles with the right conditions for release. AGR-2 fuel will soon be available for testing to address the issue of the decaying ${ }^{110 \mathrm{~m}} \mathrm{Ag}$ inventory; Compacts can also be selected that have higher silver retention to begin with (Compact 4-2-2 released $60 \%$ of its inventory during irradiation). It would also be helpful if the uncertainty in the silver collection efficiency on the deposition cups can be addressed. Progress has recently been made to reduce the deposition cup temperature, which should improve and stabilize the collection efficiency.

Future tests should concentrate on temperatures in the $1150-1300^{\circ} \mathrm{C}$ regime and hold these temperatures for longer testing periods; perhaps limiting each test to a single safety test temperature to allow for postsafety test determination of the average deposition cup collection efficiency for use in estimating timedependent compact releases. Testing particles that have been removed from irradiated compacts would be advantageous if the loose particles behave in a similar manner during the heating tests. Individual particle heating tests would allow for pre-test ${ }^{110 \mathrm{~m}} \mathrm{Ag}$ inventory measurement with IMGA, which would give more definitive silver release data and allow for targeted microstructural analysis after the test. A shakedown test for measuring fission product release from loose particles has recently been completed, where particles deconsolidated from Compact 4-4-2 were heated in the CCCTF at $1800^{\circ} \mathrm{C}$ for 650 hours; results from that test are being analyzed. Individual particle heating tests are also being considered using smaller furnaces capable of heating particles for long periods in various atmospheres. These small furnace tests would not include the time-dependent monitoring available with the CCCTF, but could be run for extended periods and explore more numerous test conditions without the resource load required to operate the CCCTF. 


\section{ACKNOWLEDGMENTS}

This work was supported by the U.S. Department of Energy, Office of Nuclear Energy, under the Very High Temperature Reactor Technology Development Office Advanced Gas Reactor Fuel Development and Qualification Program. Analysis of leach solutions and CCCTF furnace components was provided by the ORNL Nuclear Analytical Chemistry \& Isotopics Laboratory. Hot cell activities were supported by the staff of the ORNL Irradiated Fuels Examination Laboratory (IFEL).

\section{REFERENCES}

Baldwin, C.A., J.D. Hunn, R.N. Morris, F.C. Montgomery, C.M. Silva, and P.A. Demkowicz. 2012. "First Elevated Temperature Performance Testing of Coated Particle Fuel Compacts from the AGR-1 Irradiation Experiment." Paper HTR2012-3-027. Proceedings of the HTR 2012. Tokyo, Japan October 28-November 1, 2012. Also published in Nucl. Eng. and Design 271 (2014) 131-141.

Demkowicz, P.A., L.T. Cole, S.A. Ploger, and P.L. Winston. 2011. AGR-1 Irradiation Test Train Preliminary Inspection and Disassembly First Look. INL/EXT-10-20722, Rev. 0. Idaho National Laboratory, Idaho Falls, ID.

Demkowicz, P.A., J.M. Harp, P.L. Winston, and S.A. Ploger. 2013. Analysis of Fission Products on the AGR-1 Capsule Components. INL/EXT-13-28483, Rev. 0. Idaho National Laboratory, Idaho Falls, ID.

Demkowicz, P.A. 2014. Irradiated AGR-1 Compact 4-2-2 Examination Plan. INL/MIS-14-31934. Idaho National Laboratory, Idaho Falls, ID.

Demkowicz, P.A., J.D. Hunn, S.A. Ploger, R.N. Morris, C.A. Baldwin, J.M. Harp, P.L. Winston, T.J. Gerczak, I.J. van Rooyen, F.C. Montgomery, and C.M. Silva. 2014. "Irradiation Performance of AGR-1 High Temperature Reactor Fuel." Paper HTR2014-31182. Proceedings of the HTR 2014. Weihai, China, October 27-31, 2014.

Harp, J.M. 2013. Analysis of Individual Compact Fission Product Inventory and Burnup of the AGR-1 TRISO Experiment Using Gamma Spectrometry. INL/ECAR-1682, Rev. 2. Idaho National Laboratory, Idaho Falls, ID.

Hunn, J.D., and R.A. Lowden. 2006. Data Compilation for AGR-1 Variant 3 Coated Particle Composite LEU01-49T. ORNL/TM-2006/022, Rev. 0. Oak Ridge National Laboratory, Oak Ridge, TN.

Hunn, J.D., F.C. Montgomery, and P.J. Pappano. 2006. Data Compilation for AGR-1 Variant 3 Compact Lot LEU01-49T-Z. ORNL/TM-2006/510. Oak Ridge National Laboratory, Oak Ridge, TN.

Hunn, J.D., T.W. Savage, and J.S. Kehn. 2012. AGR-1 Irradiated Compact 6-4-2 PIE Report: Preparation and Analysis of Polished Compact Sections. ORNL/TM-2012/285. Oak Ridge National Laboratory, Oak Ridge, TN.

Hunn, J.D., T.W. Savage, and C.M. Silva. 2012. AGR-1 Fuel Compact Pre-Irradiation Characterization Summary Report. ORNL/TM-2012/295. Oak Ridge National Laboratory, Oak Ridge, TN.

Hunn, J.D., R.N. Morris, and C.A. Baldwin. 2012. Safety Tests on Irradiated AGR-1 Compacts 3-3-2, 3-2-2, and 6-2-1. ORNL/LTR-2012/396. Oak Ridge National Laboratory, Oak Ridge, TN.

Hunn, J.D., R.N. Morris, C.A. Baldwin, F.C. Montgomery, C.M. Silva, and T.J. Gerczak. 2012. AGR-1 Irradiated Compact 6-1-1 PIE Report: Evaluation of As-Irradiated Fuel Performance using Leach Burn Leach, IMGA, Materialography, and X-ray Tomography. ORNL/TM-2012/233. Oak Ridge National Laboratory, Oak Ridge, TN.

Hunn, J.D., R.N. Morris, C.A. Baldwin, F.C. Montgomery, C.M. Silva, and T.J. Gerczak. 2013-1. AGR-1 Irradiated Compact 4-4-2 PIE Report: Evaluation of As-Irradiated Fuel Performance with Leach Burn Leach, IMGA, Materialography, and X-ray Tomography. ORNL/TM-2013/236. Oak Ridge National Laboratory, Oak Ridge, TN. 
Hunn, J.D., R.N. Morris, C.A. Baldwin, F.C. Montgomery, C.M. Silva, and T.J. Gerczak. 2013-2. PIE on Three Irradiated AGR-1 Compacts in FY2013. ORNL/LTR-2013/291. Oak Ridge National Laboratory, Oak Ridge, TN.

Hunn, J.D., R.N. Morris, C.A. Baldwin, and F.C. Montgomery. 2014-1. Safety-Test on AGR-1 Compact 4-2-2. ORNL/LTR-2014/485. Oak Ridge National Laboratory, Oak Ridge, TN.

Hunn, J.D., R.N. Morris, C.A. Baldwin, F.C. Montgomery, and T.J. Gerczak. 2014-2. PIE on SafetyTested AGR-1 Compacts 5-3-3, 5-1-3, and 3-2-3. ORNL/TM-2014/484. Oak Ridge National Laboratory, Oak Ridge, TN.

Hunn, J.D., R.N. Morris, C.A. Baldwin, F.C. Montgomery, and T.J. Gerczak. 2014-3. PIE on SafetyTested AGR-1 Compacts 4-1-2 and 4-4-3. ORNL/LTR-2014/101. Oak Ridge National Laboratory, Oak Ridge, TN.

Hunn, J.D., C.A. Baldwin, T.J. Gerczak, F.C. Montgomery, R.N. Morris, and C.M. Silva. 2014-4. AGR-1 Irradiated Compacts 5-2-3 and 5-2-1 PIE Report: Evaluation of As-Irradiated Fuel Performance with Leach Burn Leach, IMGA, Materialography, and X-ray Tomography. ORNL/TM-2014/171. Oak Ridge National Laboratory, Oak Ridge, TN.

Morris, R.N., C.A. Baldwin, P.A. Demkowicz, J.D. Hunn, and E.L. Reber. 2014. "Performance of AGR-1 High-Temperature Reactor Fuel During Post-Irradiation Heating Tests.” Paper HTR2014-31135. Proceedings of the HTR 2014. Weihai, China, October 27-31, 2014.

Petti, D.A., J.T. Maki, J.D. Hunn, P.J. Pappano, C.M. Barnes, J.J. Saurwein, S.G. Nagley, J.M. Kendall, and R.R. Hobbins. 2010. "The DOE Advanced Gas Reactor Fuel Development and Qualification Program." JOM 62(9), 62-66.

Ploger, S.A., P.A. Demkowicz, and J.D. Hunn. 2012. Ceramographic Examinations of Irradiated AGR-1 Fuel Compacts. INL/EXT-12-25301, Rev. 1. Idaho National Laboratory, Idaho Falls, ID.

Ploger, S.A., P.A. Demkowicz, J.D. Hunn, and J.S. Kehn. 2012. "Microscopic Analysis of Irradiated AGR-1 Coated Particle Fuel Compacts." Paper HTR2012-3-020. Proceedings of the HTR 2012. Tokyo, Japan October 28-November 1, 2012. Also published in Nucl. Eng. and Design 271 (2014) 221-230.

Sterbentz, J.W. 2013. JMOCUP As-Run Daily Depletion Calculation for the AGR-1 Experiment in ATR B-10 Position. INL/ECAR-958, Rev. 2. Idaho National Laboratory, Idaho Falls, ID. 